\title{
The Role of Operational Research in Green Freight Transportation
}

\author{
Tolga Bektaş ${ }^{1 \mathrm{a}}$, Jan Fabian Ehmke ${ }^{\mathrm{b}}$, Harilaos N. Psaraftis ${ }^{\mathrm{c}}$, Jakob \\ Puchinger ${ }^{\mathrm{d}, \mathrm{e}}$ \\ ${ }^{a}$ Centre for Operational Research, Management Science and Information Systems \\ (CORMSIS), Southampton Business School, University of Southampton, \\ T.Bektas@soton.ac.uk \\ ${ }^{b}$ University of Madgeburg, Management Science Group, jan.ehmke@ovgu.de \\ ${ }^{c}$ Department of Management Engineering, Technical University of Denmark, \\ hnpsar@dtu.dk \\ ${ }^{d}$ Laboratoire Genie Industriel, CentraleSupélec, Université Paris-Saclay, France \\ ${ }^{e}$ Institut de Recherche Technologique SystemX, Paris-Saclay, France, \\ jakob.puchinger@irt-systemx.fr
}

\begin{abstract}
Recent years have witnessed an increased awareness of the negative external impacts of freight transportation. The field of Operational Research (OR) has, particularly in the recent years, continued to contribute to alleviating the negative impacts through the use of various optimization models and solution techniques. This paper presents the basic principles behind and an overview of the existing body of recent research on 'greening' freight transportation using OR-based planning techniques. The particular focus is on studies that have been described for two heavily used modes for transporting freight across the globe, namely road (including urban and electric vehicles) and maritime transportation, although other modes are also briefly discussed.
\end{abstract}

Keywords: transportation, freight, maritime, road, environment.

\section{Introduction}

The world population, currently estimated at 7.6 billion, is expected to rise by about $50 \%$ by 2100 , according to the figures given by the United Nations

\footnotetext{
${ }^{1}$ Corresponding author.
} 
Department of Economic and Social Affairs ${ }^{2}$. As such, the movement of freight will continue to be vital not just for economic prosperity, but also for social welfare. Freight is moved across the globe by using various modes of transport. Despite the significant work that has been done to improve the efficiency and effectiveness of distribution activities over the years, transport has been and continues to be detrimental on the environment.

The type and nature of the so-called negative externalities (or external costs) of transport range from one mode to another, but they generally fit under one of the following categories: (i) Emissions, including greenhouse gases (GHGs) and air pollution, (ii) noise, (iii) land use and (iv) safety hazards including accidents. Reduction of emissions, in particular, has been the main focus of international agreements on climate change as GHGs have been linked to increases in global temperatures. The primary source of energy used by the global transport sector has been petroleum products, in particular gasoline, diesel, fuel oil and jet fuel, the demand for which is expected to increase by $30 \%-82 \%$ between 2010 and 2050 over the 2010 levels, pushing the total $\mathrm{CO}_{2}$ emissions up from anywhere from $16 \%$ to $79 \%$ as reported in [145]. The increase in emissions is a consequence of the fact that they are linked, and in most cases proportional, to the amount of vehicle movement, and thus fuel consumption, and have direct and indirect effects on human health and the wider ecosystem. It is for this reason that the rest of the exposition will inevitably focus on this particular externality and efforts to alleviate the negative effects of emissions.

A range of disciplines, including economics, mathematics, atmospheric chemistry, physics and engineering, are already 'at work' to address the various challenges of climate change. Operational Research (OR) is no different and has also a role to play to address this challenge. The contributions of OR were previously reviewed within the broader domain of green logistics $[27,126]$. In this paper, we focus on a particular aspect of this domain, namely green transportation. Our understanding of the term green is broad in so far as mitigating or reducing the negative externalities of transportation from a decision-making perspective, as such is the nature of OR. For this reason, we leave out considerations such as policy making, technology development or social factors, as these are within the remit of some of the other disciplines mentioned above. It is not our intention to conduct and present an in-depth review, but rather point out to some key questions,

\footnotetext{
${ }^{2}$ https://www.un.org/development/desa/publications/ world-population-prospects-the-2017-revision.html
} 
models and approaches for the uninitiated reader on the topic. To this end, we particularly focus on two important modes of transport, namely road and maritime, on which there has been much more work.

We start our exposition by stating the following question that the title of the paper invites, particularly bearing in mind the ongoing contributions of other disciplines to reducing the externalities of transportation: "what role can OR play in green freight transportation?'. We provide one answer to this question in the following section.

\subsection{Win-Win solutions}

OR tools used within transportation seek to identify efficient plans, where efficiency is generally defined with respect to indicators that are measurable, usually in monetary units. The indicators that have traditionally been assumed in transportation planning have been on the basis of direct expenses (alternatively private or internal costs) born by the providers, including those related to infrastructure, equipment, vehicles, labor, and day-to-day (operational) running of the assets. To reduce externalities, a first step would be to quantify the external costs, which is often not an easy task, but not entirely impossible either (see, e.g., [50, 49, 76] for analyses on external costs for rail, truck and inter-modal transport).

The next step would be to incorporate externalities into planning tools and models, and one way to do this would be to explicitly add the cost into the overall cost function. In conceptual terms, and to serve as an example, let $x$ be a vector of the decision variables of the problem at hand, $f(x)$ represent the cost function of energy input associated with $x, c(x)$ be a function denoting other types of internal cost, and $m(x)$ denote a function of the associated amount of (measurable) externalities. In the following, we are particularly concerned with the case where $f(x)$ is the cost of fuel and $m(x)$ is the amount of emissions. Then, a generic optimization problem is given by the following:

$$
\underset{x \in X}{\operatorname{Minimize}} \quad \omega(f(x)+c(x))+\zeta m(x),
$$

where $\omega \geq 0$ and $\zeta \geq 0$ are user-defined weights representing the relative importance the decision maker assigns to cost versus emissions, and $X$ represents the feasible solution space to the underlying transportation planning problem, usually defined by a set of constraints.

If, in the special case that externalities are directly related to $f(x)=$ $\kappa \cdot m(x)$, with $\kappa$ being a constant, the above can also be written as:

$$
\underset{x \in X}{\operatorname{Minimize}} \quad \omega c(x)+(\omega \kappa+\zeta) m(x) .
$$


The following special cases of the above problem are important:

1. The case $\omega=0, \zeta>0$, in which the problem is to minimize emissions,

2. The case $\omega>0, \zeta=0$, in which the problem is to minimize cost,

3 . The case $c(x)=0$, in which fuel cost is the only component of the total cost.

A solution $x^{*}$ is called win-win if both case 1 and case 2 have $x^{*}$ as an optimal solution. Such a solution may not necessarily exist. It is straightforward to see that, in case (3), cost and emissions are minimized at the same time, resulting in a win-win solution. It is clear that $c(x)=0$ is a sufficient condition for a win-win solution. But this is not a necessary condition, as it is conceivable to have the same solution being the optimal solution under two different objective functions.

We would see the primary role of OR in green transportation as providing a set of decision-making tools, methods and approaches that ultimately yield win-win decisions if they indeed do exist and evaluate related trade-offs in case win-win solutions are not possible. In the following, to investigate the particular role of OR in green transportation in more detail, we discuss fundamentals and recent work of green transportation along the particular modes of transportation. In Section 2, we present problem areas and solution methods for road transportation, highlighting challenging issues arising in green urban transportation as well as in the usage of environmental-friendly fleets of electric vehicles. Section 3 covers an overview of green approaches in maritime transportation. Section 4 provides references to modes that we could not cover in this overview due to limited space and focus. Section 5 summarizes our general conclusions on the state-of-the-art in green freight transportation.

\section{Road Transportation}

Road transport is the dominant mode of inland distribution activities and is the largest consumer of energy consumption ( $76 \%$ in 2011 as reported in [145]) in relation to other modes. As emissions are the predominant externality, we first start by describing the way in which they can be quantified, along with a number of examples that show the way in which such quantified measures are used for long-haul transport planning using OR methods. We will not attempt here to present a detailed review of long-haul road freight transportation which can be found in $[31,88]$. In Section 2.2 , we extend the discussion to the challenges around urban transportation and the ongoing OR contributions. Finally, Section 2.3 presents an overview of OR progress on electric vehicles as an emerging technology. 


\subsection{Quantifying externalities}

Compared to other externalities, GHG emissions, and in particular $\mathrm{CO}_{2}$, are easiest to quantify, particularly for conventional vehicles using gasoline (petrol) or diesel as fuel. This is because there exists emission (or fuel consumption) models to estimate the total energy requirement to move a vehicle from one point to another, using which it is possible to calculate the total amount of fuel required to provide the energy. The amount of carbon in gasoline or diesel is also known, using which one can estimate the amount of GHG, usually in absolute terms (e.g., grams) or rate at which they are emitted (e.g., grams/kilometer).

Emission models come in different forms depending on the way in which they are used. We will not present here a detailed exposition and instead refer the reader to comprehensive reviews on the topic [28, 31, 150]. Instead, we will show some examples to give the reader a flavor of the type of models available and their form.

- Perhaps the simplest way to calculate emissions is through the use of activity-based or factor models. In such models, one simply uses a conversion factor (e.g., kilograms of $\mathrm{CO}_{2}$ per vehicle-kilometer) and multiplies it with the amount of activity (e.g., total vehicle kilometers traveled). Conversion factors for a range of heavy goods vehicles can be found in [109] according to whom, for example, the $\mathrm{CO}_{2}$ (equivalent) per vehicle-kilometer of a rigid truck weighing between 3.5 and 7.5 tons is $0.59115 \mathrm{~kg}$, whereas the same figure for an articulated truck of at least 33 tons of weight sharply rises to 0.995873 . These factors, however, are static, and are therefore more suitable for use as an a posteriori evaluation of a given distribution plan as opposed to a priori input parameters to an optimization problem, particularly in distribution operations during the course of which either the vehicles or the loads of the vehicles are expected to change. In the latter case, a refinement procedure may be used to estimate the emission factors (see, e.g., [139]) for an iterative process in the case of vehicle routing with backhauling).

- The assessment of emissions over wide areas is usually performed through macroscopic models, which only use an average speed value $v$ that a vehicle of a certain configuration travels at. Such models are in the form of a regression model and have the general form

$$
E(v)=\sum_{i=i_{0}}^{i_{n}} \beta_{i} v^{i},
$$




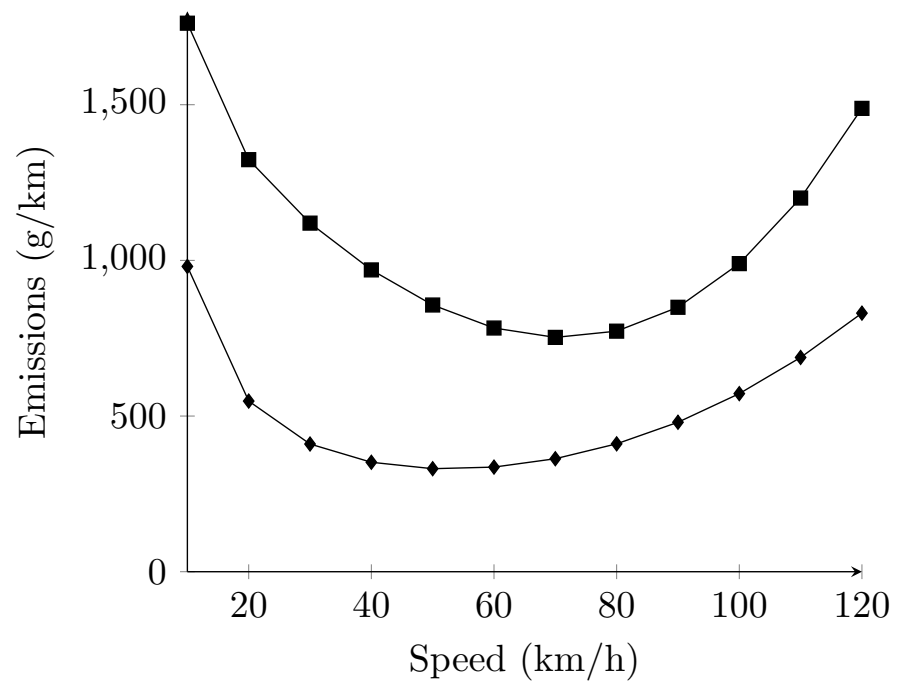

Figure 1: Emission curves according to the MEET model [63], diamond line for a lightweight truck (of weight between $3.5 \mathrm{t}$ and $7.5 \mathrm{t}$ ) and square line for a heavy weight truck (of weight above $32 \mathrm{t}$ )

where $\beta_{i}$ are the coefficients that depend on the weight class of the vehicle, and $i_{0}, \ldots, i_{n}$ are integers as powers of $v$ (in some cases $i_{0}<0$ ) corresponding to each term of the regression function. In the model above, $E(v)$ yields the rate of emissions. In some cases, one would have to further apply a correction factor $\gamma_{r}$ relevant to road grade and $\gamma_{l}$ to vehicle load as $E(v) \times \gamma_{r} \times \gamma_{l}$. One such model named MEET is given in [63] and is shown in Figure 1 for two types of trucks. Such curves are typical of most (if not all) emission models.

- For heavy goods vehicles, more complicated models exist that estimate the emissions on a second-by-second basis using instantaneous parameters. These are generally referred to as microscopic models. At the heart of these models lies the calculation of total tractive power required to move a vehicle $[124,11]$. This power itself is a function of a number of vehicle and road-related parameters, including the speed $v$ of the vehicle and the laden weight $w$ of the vehicle comprising the tare weight of the vehicle and weight of the goods. If all the parameters remain constant over a journey of $d$ units long, then a basic form for calculating the total energy can be given as a function $P(w, v)$ of load and speed and expressed as below, stated in a similar form as in 
[87]:

$$
P(w, v)=\alpha(w \times d)+\beta\left(v^{2} \times d\right) .
$$

In the equation above, $\alpha$ is a constant quantified by parameters such as the acceleration of the vehicle, the road gradient, the rolling resistance and the gravitational constant. The other constant $\beta$ includes terms such as the drag coefficient, frontal surface area of the vehicle and the density of the air around the vehicle. Once $P(w, v)$ is calculated, it is converted into engine power requirement as $P(w, v) / \eta$ by taking engine efficiency $\eta$ (usually $\ll 1$ ) into account, and subsequently converted into fuel rate $F(w, v)$ by taking engine specific parameters into account.

GHGs are not the only emissions from vehicles, however. Air particular matter, for example, is also emitted into the atmosphere, not only as a result of tailpipe emissions, but also due to road dust, from worn tires and break linings, as well as the resuspension of other particles in the nearby environment [122].

As suggested by the brief description of emissions above, there exist a wide range of factors affecting fuel consumption of vehicles used in long-haul road transportation, which can broadly be categorized in three categories:

- Vehicles, including type and design, mechanical features such as engine size and engine efficiency, as well as the condition of engines, tires, filters, etc.

- Environment, including the topography and geographical features of the $\operatorname{road}(\mathrm{s})$ that the vehicles are driven on, such as the road gradient and drag, the ambient temperature, wind conditions, as well as the traffic conditions such as congestion.

- Driving, which is related to the way in which the vehicle is driven. For vehicles with human drivers, this would include driver behavior affecting gear selection, rate of acceleration and deceleration, choice and variability of speed and idling. In case of autonomous vehicles, such factors are still relevant but possibly with much less variability.

\subsubsection{Decisions}

The effects of some of these factors can be addressed through, e.g., maintenance for vehicles and training for drivers, but these are beyond the scope of OR techniques. The primary role of OR on improving the fuel economy for 
road transportation manifests itself at three main levels of decision making, mainly from the point of view of transport planning ${ }^{3}$ :

- Strategic and Systemic: These decisions concern the design, redesign or expansion of the transportation network with an explicit integration of environmental aspects into existing models either as new objective(s) or constraints. The existing studies on this aspect are limited and are mostly rooted in supply chains, making use of strategies such as redesign of distribution structures, centralizing warehousing and consolidation of flows, changes in the use of transport mode (e.g., shifting from road to rail), and a judicious selection of facility locations. An introduction and a review to the topic is given by [61]. It is clear that such decisions lead to modifications of existing networks, would be costly to implement and require a certain time before the distribution network is made fully operational again. In contrast, other types of decisions at a system level can be made that do not necessarily require such huge and strategic investments. One good example is setting toll prices [see, e.g., 142] to influence the traffic conditions in an attempt to minimize overall emissions on a given road network.

- Tactical: Tactical decisions to improve the environmental performance of road transportation generally include the choice of the fleet of vehicles to be used in the routing, of which there are a number of options. In particular, there exist eight classes of trucks with a gross vehicle weight rating, defined as the maximum allowable total weight of the vehicle including its empty mass, fuel and any load carried, ranging from three to over 15 tonnes. Each type of truck will vary in terms of the maximum payload that can be carried and design characteristics and features (including engine parameters), all of which affect fuel consumption. A heterogeneous fleet of vehicles generally has better environmental performance as compared to a homogeneous and is also less costly, as evidenced by studies carried out independently [82, 80, 38]. Within fleet management, there may be further environmental as well as economic benefits to reap in the case of distribution with back-

\footnotetext{
${ }^{3}$ Our classification is of a different perspective as compared to that described in [131], which treats the decisions from the point of view of a driver, namely strategic including vehicle selection (class, model) and maintenance (engine, tires, engine oil), tactical comprising selection of road type, gradient and traffic profile (i.e., avoiding congestion), and operational that concerns the micro-level driving decisions such as idling, speed and aggressiveness.
} 
hauling. In particular, the study [139] provides quantified evidence to show that an explicit consideration of backhauling in vehicle routing reduces the empty-running of the vehicles, and is an effective strategy in controlling emissions, resulting in better use of truck capacity and increased fleet efficiency.

- Operational: There are a number of decisions to be made at this level and they depend on the time frame in which they can be implemented, as discussed below:

- Macro-level: The main operational level decision that can be taken to improve the environmental performance of road transport is through consolidation, giving rise to a vehicle routing problem where each vehicle in a fleet serves a number of customers, either for delivery or collection, where the optimization concerns assigning customers to vehicles and determining the sequence of visits of each vehicle. These are usually the 'day-before' decisions and cannot (easily) be changed once made and implemented, particularly in parcel or cargo distribution, where the packing is completed on the basis of the sequencing decisions. The assignments will determine the total load of each vehicle, and the sequence will influence the load between subsequent visits on a route, both of which will affect the energy requirement and consequently the fuel consumption. One relevant work is by Kara et al.[78], who introduce an energy minimizing vehicle routing problem, where the cumulative loads of individual vehicles is minimized so as to reduce the energy required. The general form of this formulation is as follows:

$$
\begin{aligned}
\text { Minimize } & E(w(x), d(x)) \\
\text { subject to } & x \in X,
\end{aligned}
$$

where $X$ is the set of all feasible routes, $x$ is a vector comprising a route for each vehicle, $d(x)$ is the total distance of the routes in $x$ and $w(x)$ is the loads of the vehicles on each route of $x$. The energy function $E(w(x), d(x))$ is a weighted load function defined as the sum of the product of the arc length and the weight of the vehicle on the arc over all arcs used. The state-of-the-art in solving this problem optimally is through the use of a branchand-cut-and-price algorithm [52]. 
One other relevant work at this level of decision making is the pollution-routing problem first described by [13], where a more comprehensive emission function is minimized within a vehicle routing setting, but this problem takes into account another set of (meso-level) decisions, namely vehicle speeds $v$, in an attempt to optimize the speed of each vehicle on each leg of the journey. A simplified model of the pollution-routing problem can be given as follows:

$$
\begin{aligned}
\text { Minimize } & F(w(x), v) \\
\text { subject to } & x \in X^{\prime} \\
& x \leq B v \\
& v^{l} \leq v \leq v^{u} .
\end{aligned}
$$

In this formulation, the objective (7) aims to minimize the total fuel consumption by optimizing the routes and the speeds, and where the vehicle loads $w(x)$ again depend on the route chosen. The set $X^{\prime}$ contains all feasible routes that also satisfy time windows of the customers. Constraints (9) model the link between vehicle speeds and the routes through the use of a suitable coefficient matrix $B$, namely the requirement that a speed has to be chosen for each leg of a route selected. The speeds have to be within legal limits $\left[v^{l}, v^{u}\right]$ as indicated by constraints (10). In the original formulation of [13], the objective function also considers driver costs that increase with the time spent en-route, but this is often in conflict with the desire to slow down to minimise energy, although the trade-off is not always so strict [30]. Finally, the quadratic nature of the objective function (7) that follows the energy calculation shown in (4) results in a mixed integer nonlinear programming formulation. The challenge of solving such a formulation can be overcome by either transforming the model into a mixed integer linear programming formulation by discretizing speeds as done in [13], or by using convex programming techniques as described in [54, 53].

- Meso-level: It is known that the speed of a vehicle is a primary determinant of fuel consumption, but it also affects the duration of the journey with impacts on driver cost and the timing of customer visits (e.g., for time-sensitive deliveries). Scheduling decisions for vehicles on fixed routes can therefore reduce 
energy requirements [87] by optimizing the speed used at each leg of the journey, especially in a long-haul environment. This so-called speed optimization problem problem finds its origins in maritime routing for which optimal methods exist [72] and has been adapted to road transportation by taking driver costs into account [29]. A formulation for the speed optimization problem defined on a given route $(0,1, \ldots, n)$ of $n$ customers, each requiring service within the time windows $\left[a_{i}, b_{i}\right], i=1, \ldots, n$, can be given as follows:

$$
\text { Minimize } \quad \sum_{i=1}^{n-1} d_{i, i+1} f\left(v_{i, i+1}\right)+D\left(t_{n}\right)
$$

subject to

$$
\begin{aligned}
t_{i+1}-t_{i}-d_{i, i+1} / v_{i, i+1} & \geq 0 \\
a_{i} & \leq t_{i} \leq b_{i} \\
v_{i}^{l} & \leq v_{i} \leq v_{i}^{u} .
\end{aligned}
$$

In this formulation, $d_{i, i+1}$ is the distance between a successive pair of nodes $i$ and $i+1$ on the route, $f\left(v_{i, i+1}\right)$ is the fuel consumption function and $D\left(t_{n}\right)$ is the driver cost depending on the total time $t_{n}$ spent on the journey. The decision variables are the speeds $v_{i-1, i}$ to use between successive nodes, subject to the bounds (14), which will determine the time $t_{i}$ that service will commence at node $i$ in a way that the time window constraints (13) are respected. The formulation above is a nonlinear (continuous) programming formulation but can be solved optimally provided the objective function is convex [72]. Further extensions have been studied by including the departure time [85] in the optimization and in settings where there is a period of congestion [51].

- Micro-level: At the micro-level, the main question is how to optimally drive a vehicle on a given road segment, the answer to which lies in making optimal decisions about acceleration and speed as a function of time of travel. Some very interesting work has been carried out in the 1980s, including those by Hooker et al. [68] and Hooker [67], who used optimal control and dynamic programming to find optimized driving profiles to maximize fuel economy. 
The optimal control problem described in [67] assumes that the rate $f(v, a)$ of fuel consumption of a vehicle depends on the speed $v$ at which the vehicle moves and the acceleration rate $a$, subject to a maximum value $\bar{a}(v)$. The vehicle is to traverse a segment of road of length $s_{1}$, with an initial speed $v_{0}$, and where the road angle $\theta(s)$ is given for any distance $s$ from the starting point. The simplified mathematical model is as follows:

$$
\begin{array}{ll}
\underset{v, T}{\operatorname{Minimize}} & \int_{0}^{T} f(v(t), a(t)) d t \\
\text { subject to } & \\
& \dot{s}(t)=v(t) \\
& a(t)=\dot{v}(t)+g \sin \theta(s(t)) \\
& a(t) \leq \bar{a}(v(t)) \\
v(0) & =v_{0} \\
s(0) & =0 .
\end{array}
$$

In the above, $s(t)$ is the distance covered by the vehicle at time $t$ measured from the starting point and (17) is the system equation. An additional constraint in the form of $s(T)=s_{1}$ may be added to the formulation. The objective is to minimize the total fuel consumption shown by (15) by optimizing the speed trajectory $v(t)$ and duration $T$. The special cases of the above problem studied in [67] consist of the cruising problem that seeks to find an average speed both on a level road (with the road grade equal to zero) and over hills (where the road grade is positive), the acceleration problem in moving from rest to cruising speed and driving between a given pair of nodes, starting and ending at rest. The problem above can be solved by dynamic programming where the speeds and the positions of the vehicle are discretized. This line of work was extended by [97], where the objective is to minimize a weighted combination of fuel consumption and time. This body of work has received, and continues to receive, good interest from the transportation research community, including use of optimal control to reduce externalities, see, e.g., [91]. However, it does not seem to have had much take up from within the domain of OR. 


\subsection{Urban transportation}

Increasing popularity of metropolitan areas in the last decades has raised awareness for environmental issues of transportation with researchers in the field of OR. In urban areas, space is very limited, and given the limited transportation infrastructure, road transportation causes congestion and a significant amount of emissions such as $\mathrm{CO}_{2}$ emissions. There are generally two approaches to address environmental issues in urban transportation: optimizing the design of transportation networks, and optimizing the operations of urban transportation services. In the following, we present a selection of relevant OR-related work that has a particular focus on road transportation in urban areas and addresses environmental issues of urban transportation.

\subsubsection{Optimizing the design of urban transportation networks}

A well-known approach at making urban transportation networks greener is the reorganization of supply chains by means of city logistics concepts. The idea of city logistics is to reduce the negative external effects of freight transportation but also to acknowledge its important role in the supply of dense urban areas. This comprises the organization of urban freight transportation such that requirements of all relevant stakeholders are considered, i.e., municipalities, shippers, retailers, and citizens [137]. From a transportation network design perspective, the core idea is to consolidate long-haul transports in city distribution centers (CDCs, [25]). As CDCs are typically located at the city border, smaller, environmental-friendly vehicles can take over the transport of goods on the last mile to the final recipient within city borders. This requires synchronization between long-haul and last-mile vehicles. A recent overview of approaches to routing in city logistics and synchronization between different city logistics tiers is provided by Cattaruzza et al. [19].

A common variant of city logistics that has raised considerable attention in the OR community is the two-echelon problem. Goods are first transported from the CDC to "satellites" (first tier), where they are transshipped and then transported to the final recipient by small, environmental-friendly vehicles (second tier). Anderluh and Hemmelmayr [6] present a recent example for a green concept of such a two-echelon network. Based on a case study for the city of Vienna, they synchronize freight between cargo vans operating on the first tier and cargo bikes operating on the second tier. They develop a greedy randomized adaptive search procedure and compare three distribution policies to evaluate the sustainability of their city logistics concept: direct delivery, two-echelon deliveries based on cargo vans and cargo bikes 
that transship goods at satellites, and "mobile" satellites that require exact synchronization between the tiers. They highlight that synchronization is costly, but can be advantageous in terms of minimizing emissions.

Koç et al. [81] analyze the interplay of depot location, fleet composition and routing decisions with regard to their impact on emissions in urban areas. Their objective is to minimize the total costs consisting of the depot operating cost, fixed vehicle cost, and fuel and $\mathrm{CO}_{2}$ emissions cost. Three vehicle types are considered (two light duty and one medium duty vehicle). Furthermore, minimum emissions are determined according to predefined speed zones, but the impact of congestion is ignored. Depot costs vary according to depot location (e.g. location within the downtown area or within the suburbs). Fuel consumption is modeled with a microscopic emissions model, the comprehensive emissions model (CEM, see Section 2.1). The problem is solved with an adaptive large neighborhood based metaheuristic. Computational experiments show that the minimum-cost path is not always the fastest, cheapest or least polluting path. Furthermore, using a heterogeneous fleet can decrease total cost significantly, as well as choosing a depot location outside the city center.

Tricoire and Parragh [138] focus on investigating the trade-off between minimizing costs and minimizing $\mathrm{CO}_{2}$ emissions in the context of a locationrouting problem. They consider the cost of different depot locations anticipating daily logistics operations for different types of vehicles and resulting routes. The problem is modeled as a mixed integer program based on a set covering formulation. The applicability of the model in a city logistics context is exemplified for a case study of the city of Vienna.

\subsubsection{Optimizing green urban transportation services}

Since traffic is often slow in urban areas and freight vehicles have to adjust their speed level to the surrounding traffic, they cannot drive at the emissions-optimal speed in urban areas as provided by a fuel consumption model presented in Figure 1, for example. Optimizing routes for distances or travel times as proposed by the majority of routing approaches may indirectly support environmental goals, but in the end, minimizing for distances or travel times does not guarantee the creation of green, minimum emissions routes [37]. More complex modeling and solution techniques are needed, which rely on detailed speed data to incorporate the effects of stochastic and time-varying speeds. The required data has become available to a large extent in recent years [35]. However, it is still challenging to create appropriate data aggregates, align them with optimization models and develop solution procedures for green urban routing. Figure 2 highlights the flow of 


\begin{tabular}{|c|c|c|c|c|c|}
\hline $\begin{array}{l}\text { Emissions } \\
\text { Modelling }\end{array}$ & $\begin{array}{l}\text { Digit } \\
\text { Roant }\end{array}$ & $\begin{array}{l}\text { Minimum } \\
\text { Emissions Path }\end{array}$ & $\begin{array}{l}\text { Load-Ind } \\
\text { Fuel Cons }\end{array}$ & $\begin{array}{l}\text { Minimum } \\
\text { Emissions Tour }\end{array}$ & $\begin{array}{l}\text { Load- } \\
\text { Dep } \\
\text { Tour }\end{array}$ \\
\hline Data Collection & & Path Finding & tા & Routing & Plans \\
\hline
\end{tabular}

Figure 2: Tasks and flow of information in green urban transportation, adapted from [59]

data as well as the particular optimization tasks required to optimize green urban transportation services.

Given that appropriate speed data is available, the first step is to include these in appropriate fuel consumption models to estimate emissions on the dense road network of urban areas. For instance, microscopic fuel consumption models require detailed information such as expected speeds or travel times, travel time variation, gradient of the road, etc. In the next step, this information needs to be considered in the computation of minimumemissions paths. The challenge is that the minimum-emissions path may vary according to the type of vehicle, time of day, and load carried on the path, which is called "path flexibility" by some authors [71]. Hence, it is not possible to precompute all the required paths in general [38]. However, it is often possible to precompute the load-independent portion of the minimumemissions path, which can reduce the computational efforts of green routing significantly. As a last step, green pickup and delivery tours need to be created, which again depend on type of vehicle, time of day, as well as load carried between the affected customers. In the following, we will highlight recent approaches that address these issues.

Minimum emissions paths. Given the non-linearity of fuel consumption functions, considering environmental objectives in path finding is challenging. In urban areas, we know that there are certain patterns of speed variation because of recurring congestion over the course of the day, and the minimum emissions path becomes time and load-dependent. For instance, in an environment of heavily varying travel times and due to the non-linearity of fuel consumption models, it may be optimal to select a shorter path with an empty truck, but it may be advantageous to switch to a longer path when fully loaded. Ehmke et al. [37] present two heuristics that find such minimum-emissions paths in stochastic and time-dependent urban road networks. To capture the variability of speeds, the heuristics expect large 
amounts of speed data. The first heuristic incorporates sampling into an extended $A^{*}$ algorithm. For each arc, multiple emission and travel time values are considered based on a time-dependent sampling of the observed speeds, leading to multiple arrival times and emission values at the tail node. The sampled set of arrival times and emission values is used as an approximation of the distribution of arrival times and emissions. Since this requires significant computational power, the authors present a second heuristic, where the network search is simplified through time discretization and aggregated labels instead of considering all individual emission and travel time observations. Computational experiments with a large travel time database of Stuttgart, Germany, show that losses of the second heuristic compared to the first stochastic technique are negligible. Using the CEM, Heni et al. [62] develop time-dependent lower and upper bounds for the minimum-emissions path, minimizing a combined objective of emissions, driver and congestion costs. They investigate when it is important to incorporate load and congestion into path finding and present a variant of Dijkstra's algorithm for this problem. They apply their algorithm to the network of Quebec City and are able to show that alternative paths can reduce fuel consumption significantly.

Hwang and Ouyang [73] propose two approaches for finding minimumemissions paths in urban road networks, but focus on minimizing expected total costs, which includes total delivery time, emissions, and a penalty for late arrivals. They assume that the speed on each arc follows a known, independent probability distribution. Their stochastic path finding approach is based on dynamic programming, resulting in relatively long run times, and a deterministic alternative that provides slightly inferior solutions at much shorter run times. They present four case studies and conclude that modeling fuel consumption as a function of travel speed, particularly variable speeds, leads to paths with total costs different than the paths chosen when the speed variability is ignored.

Many metropolitan areas have reacted to increasing traffic of freight vehicles by charging daily or hourly tolls. These "congestion charges" are raised when vehicles enter a specific downtown area, and they are often implemented by means of a daily (or hourly) fee, as it is the case for downtown London, for example. Wen et al. [143] present two heuristics that compute minimum-cost paths in deterministic, time-dependent urban road networks with congestion charges. In the paper of Wen et al., the cost objective consists of fuel cost, driver cost and the possible congestion charges. The fuel cost is computed according to the emissions factor database of the National Atmospheric Emissions inventory (naei.defra.gov.uk). The challenge is that 
in this time-varying network with congestion charges, the cost consistency constrained is not fulfilled. This means that leaving a node earlier does not necessarily cost less than leaving a node later. Hence, standard path finding methods such as Dijkstra's algorithm cannot guarantee finding the minimum-cost path. Furthermore, the minimum-cost path may change depending on whether a congestion charge has to be paid or not. Employing concepts of Dijkstra's network search, two heuristics are presented: heuristic 1 enables the revisiting of nodes, and heuristic 2 considers all instead of only the minimum labels, which leads to long run times and memory issues. A benchmark dataset is created and the heuristics are applied to the city road network of London.

Strehler et al. [134] determine energy-efficient paths for hybrid and/or electric vehicles (see also Section 2.3). Since recharging of an electric vehicle takes much longer than refueling of conventional vehicles, they consider detailed information about the road network and the charging state of the battery to determine the best trade-off between range and speed in path finding. They solve a constrained shortest path problem with convertible resources and charging stations. They allow for recharging at nodes (charging stations) as well as on edges (e.g. through recuperation). Since energy-efficient paths may contain cycles, the authors claim that traditional shortest path problems are not a sufficient approximation for the input data required by more complex problems such as vehicle routing problems.

Finding environmental-friendly route plans. Once information on minimumemissions paths has been derived, green route plans can be created. Especially relevant for urban areas, the presented vehicle routing approaches differ in their capability to consider time- and load-dependent path flexibility. Bektaş and Laporte [13] minimize $\mathrm{CO}_{2}$ emissions by determining the optimal speed level for a given load and assume that the vehicle will travel at that speed. They do not have a specific urban focus and only consider speeds of $40 \mathrm{~km} / \mathrm{h}$ or higher. They compute emissions based on the CEM. As highlighted above, this is the fundamental paper of the pollution routing problem, which focuses rather on long-haul road transportation than on specifics of urban areas, where it is usually not possible to always follow an optimized speed level to minimize total cost or environmental impact. Still, this paper has motivated important extensions for urban green routing.

Addressing green routing particularly in urban areas, Jabali et al. [74] consider time-dependent travel times in the minimization of operational costs, fuel consumption and emissions. Extending the ideas of Bektaş and Laporte [13] for congested time periods, they assume that speeds are fixed, 
and outside these periods, speeds are optimized to minimize emissions. Solutions are created based on a tabu search approach. In a similar setting, Franceschetti et al. [51] create a time-dependent variant of the pollution routing problem considering time-dependent fuel consumption and driver costs. As Jabali et al. [74], they consider an uncongested period (with relatively high speeds and lower emissions) and a congested period (with relatively low speeds and higher emissions). Fuel consumption is modeled with the CEM. They enable waiting in their route plans (at the depot or at customers) to avoid having vehicles run into congested periods. An integer program is presented and benchmark instances are solved with CPLEX.

Qian and Eglese [118] create a single route that minimizes emissions, not accounting for the varying load of the vehicle. They choose the order of customer visits as well as the vehicle speed and the amount of waiting time at the customers. Vehicles may travel below the speed limit, and the speed limit varies with time. They present two methods to solve the problem, one of which is based on dynamic programming. They compare their solutions with the fastest routes serving the same customers and show that emissions can be minimized with 9-10\% more trip time. Qian and Eglese [119] minimize $\mathrm{CO}_{2}$ emissions in a time-dependent urban road network with customer time windows. They decide about the chosen paths and about the speeds that are driven on the individual paths. They also allow for waiting at customers in order to avoid running into congested time periods. The solution approach is a tabu search combined with column generation. It is tested on London instances considering real traffic data. Figliozzi [48] also minimizes fuel consumption considering time-varying speed, but does not consider varying load in the minimization of emissions. Travel speeds are controlled by waiting at customer locations, and customers have time windows. Hosseini-Nasab and Lotfalian [69] create multiple paths between customer locations that differ in travel time, fuel consumption and distance. They classify paths according to the speed level and consider different penalties for using these paths in the minimization of energy for a fleet of vehicles. The routing problem is solved for small instances with XPRESS.

Xiao and Konak [147] present a mixed integer linear program to create routes that minimize emissions in urban areas along similar lines as Figliozzi [48], but consider a heterogeneous fleet of vehicles. They solve the problem for 20 small instances and analyze differences of the emissionsoptimal solutions in terms of distance, travel time and total $\mathrm{CO}_{2}$ emissions. They also present a variable neighborhood based solution approach that is suitable for larger instances. Xiao and Konak [146] minimize $\mathrm{CO}_{2}$ emissions of heterogeneous fleets with time-dependent traffic conditions and varying 
load of the vehicles. They present a mixed integer linear programming model and an exact solution approach based on dynamic programming as well as a hybrid solution approach including a genetic algorithm. Emissions are modeled by the CEM. Soysal and Çimen [132] propose a dynamic programming approach for the time-dependent green routing problem. This model ignores the varying load of the vehicle and also the possibility of flexible paths. Emissions are approximated by the COPERT2 model. Due to limitations caused by exponential run time requirements, they also present a simulation-based restricted dynamic programming approach, considering weighted random sampling. Computational experiments are based on a real-world case, namely the distribution of pharmaceuticals from a central warehouse to pharmacies in urban areas, and show small improvements when avoiding congested time periods.

Huang et al. [71] explicitly model time dependency in a vehicle routing problem in urban areas, where the optimal paths may change depending on the load of the vehicle and the time of day. Based on the CEM, they minimize total cost including a complex formulation for total fuel consumption. The authors employ a scenario-based stochastic mixed integer programming approach to analyze the impact of stochastic information. To overcome the enumeration of every possible path, they rely on a pre-computed, limited set of paths between each customer pair and select the best path from this set as needed. Norouzi et al. [101] present a multi-objective approach to green urban routing, minimizing total fuel consumption as well as total travel time through a weighted sum approach. They consider time-dependent travel times and the varying load of the vehicle. The heuristic solution approach is based on a particle swarm optimization algorithm and applied to Solomon instances. Wen and Eglese [141] consider a time-dependent urban network with congestion charges and minimize total operational cost, consisting of fuel cost, driver cost and congestion charge. Köster et al. [83] present a routing approach where logistics service providers know the signal plans of the city's traffic signals and can anticipate them in the routing of their delivery vehicles to increase reliability of delivery and decrease $\mathrm{CO}_{2}$ emissions.

Kuo [86] compares results of time and load-dependent route plans minimizing distances, travel times and fuel consumption individually. The author presents a simulated annealing based solution approach, and computational experiments with Solomon instances show significant differences between routes created by the different objectives. Ehmke et al. [38] also compare the results of urban vehicle routing for different objectives (minimizing distance, travel time, and fuel consumption), employing the CEM as presented by Franceschetti et al. [51]. They consider the impact of varying load on 
emissions in the environment of time-dependent travel times. They use the results of Ehmke et al. [37] to create time and load-dependent emissionsminimizing paths. They also consider mixed fleets with small and large trucks that create a different amount of emissions. Computational experiments are based on a real road network of a German city and a corresponding large database of speed observations. Speed observations are used to estimate expected emissions and travel times of individual arcs and routes. The results show that considering this level of detail pays off especially for longer suburban routes with heavy vehicles. The results also show that emissionsminimized paths increase route durations proportionately less than duration minimized routes increase emissions. Ehmke et al. [36] extend this by comparing a combined cost objective consisting of driver and fuel cost. They provide a summary of the most recent green routing approaches - not necessarily with urban focus - and distinguish them by parameters such as objective, fuel consumption model used, and ability to consider path flexibility.

Çimen and Soysal [20] consider the impact of stochastic travel speeds on the time-dependent green vehicle routing problem. They minimize expected total routing cost including expected cost of fuel consumption and labor cost and use the MEET model to approximate the fuel consumption, ignoring variation of load between the individual customers. They model the problem as Markovian Decision Process and solve it with a heuristic based on approximate dynamic programming. For computational analysis, the authors use instances from the PRPLIB, and speeds are distributed according to the normal distribution. They compare minimizing expected total emissions with minimizing expected total routing cost. Computational results show that accounting for stochasticity yields an additional saving of $1.13 \%$ of total routing costs.

Feng et al. [47] model average speed on arcs between customers through a normal distribution. The presented mathematical model is based on the CEM and minimizes expected total cost including expected fuel consumption. The problem is solved by CPLEX as well as through an improved simulated annealing algorithm. Computational experiments based on the PRPLIB show that the expected fuel consumption is always larger than fuel consumption derived from a deterministic, fixed speed model.

\subsection{Electric vehicles}

Electric vehicle technology is becoming increasingly relevant in green freight transportation. The advantage of battery electric vehicles (BEV) in comparison to vehicles powered by internal combustion engines (ICEV) are the non- 
existing local pollutant emissions (GHG, particles, etc...) and lower noise pollution. The overall GHG-emissions will depend on the energy source used to produce the electricity for powering the vehicle [18].

A recent survey on goods distribution with electric vehicles [106] presents the basics of electric vehicle technology, economical aspects, and operational research aspects related to the use of electric vehicles such as vehicle routing and optimal path finding. A recent book chapter on electric-car sharing systems [14] includes several aspects related to this section, such as charging station location, optimal path finding for electric vehicles and electric vehicle routing problems.

Several peculiarities of BEVs are limiting their use in comparison to ICEVs and are leading to novel optimization problems that need to be solved in order to use them efficiently: higher initial investment, reduced range, and long recharging times.

Based on these limitations, several optimization topics related to the use of BEVs in various transport applications have emerged and will be surveyed in the following subsections: (i) optimal path finding; (ii) vehicle routing with recharging; (iii) electric location routing. Further optimization topics emerging from BEV operations such as charging station location planning or vehicle to grid operations are not treated here.

\subsubsection{Optimal Paths for Electric Vehicles}

Optimal path computation for BEVs and PHEVs include aspects going beyond typical shortest or fastest path calculations. Models and algorithms typically used for solving such problems may consider energy consumption and recuperation, travel times, recharging times, cost functions related to time and energy use, and others.

Energy optimal paths. Most algorithms used for computing energy optimal paths need to predict the energy required to traverse every road segment (or arc) of the network. The widely used longitudinal dynamics model requires information on speed, road grade, vehicle characteristics, etc. [10]. Most of the presented algorithms use a simplified longitudinal dynamics model.

As recuperation is taken into account in these types of models, arcs with negative edge weights might occur in the routing graph, thereby rendering those types of problems not solvable by directly applying algorithms based on Dijkstra's shortest path algorithm, but rather by adapting BellmanFord's algorithm [9]. However, [39] show that by applying Johnson's potential shifting approach, the problem can be transformed into a version 
solvable using Dijkstra-based algorithms. The authors show that algorithmic speed-up strategies such as contraction hierarchies are applicable to such transformed energy routing graphs and demonstrate their algorithm on large real-word problem instances.

Optimal paths including charging. Optimal recharging policies for a fixed path in a deterministic setting have been investigated in [135]. Recharging times and cost as well as the battery life cycle are taken into account. The authors determine optimal charging policies for general paths with charging allowed at some specific nodes using forward recursion. They further investigate some problem variants with regard to charging station availability (continuous and equidistant) and further propose heuristically determined policies. Numerical results on long distance travel as well as urban routes are used for evaluating the heuristic performances against the optimal policies. The authors conclude that the heuristic avoiding overcharging performs best on the long distance setting, whereas the heuristic minimizing the number of stops performs best in the urban setting.

As mentioned in Section 2.2, energy-efficient paths including recharging at nodes are determined in [134].

Optimal paths with stochastic charging station availability. Adaptive routing and recharging policies are considered in [136] extending previous work. The authors address the problem of uncertain charging station availability and wait times at charging stations, overcharging cost, and the routing of electric vehicles. Two models are considered in this work: In the first model, drivers are following a given path and decide whether to stop at a charging station upon arrival, when information about the station's availability becomes known to the driver. An optimal recharging policy is obtained for this first model by dynamic programming. Second, the selection of paths is added to the model aiming to find an optimal adaptive routing and recharging policies. As this is a more complex problem two heuristics are proposed. In a first step, an a-priori policy corresponding to an optimal route including charging that minimizes the total expected cost is determined by dynamic programming. In the second step, two solution methods for the adaptive version of the problem are proposed. In the first adaptive policy, the driver follows the path determined in the first step and is allowed to adapt the charging locations along this path. The second adaptive policy, also starting from the path determined in the first step, allows the driver to change the path and the charging locations. A numerical study on grid instances shows the advantages of using adaptive policies. Especially adaptive recharging 
is very beneficial, while combining adaptive recharging and routing further improves the results only slightly and especially for longer trips.

Routing and charging with stochastic travel times. An optimal and reliable path finding problem for electric vehicles taking into account travel time as well as charging is presented in [75]. Reliability is defined as the probability of finishing the trip without running out of charge. The charging cost is computed as the amount of energy to be charged multiplied by a charging station-dependent price. The energy consumed on each arc is a function of arc length and travel time, and arc travel times are modeled as stochastic variables. The objective is to minimize a generalized cost function modeled as linear combination of travel time and charging cost, subject to a minimum reliability level. The authors propose an a-priori algorithm based on generalized dynamic programming. It is shown that optimal solutions may include cycles including at least one recharging station. Computational experiments on random networks demonstrate that cyclic paths are rare and that costs increase with an increasing reliability level.

\subsubsection{Electric Vehicle Routing and Recharging}

The major differences between classical vehicle routing problems and vehicle routing problems for electric vehicles are their limited range, long recharging times and limited recharging station availability.

Recharging at customer locations has been considered in the recharging vehicle routing problem [23]. Electric vehicles can recharge up to a certain percentage of their maximum capacity within a fixed amount of time not depending on their state of charge. Recharging and customer service are performed at the same time. This model cannot address charging stations that are separate from customer locations and can be visited multiple times and has therefore not been much investigated.

Green vehicle routing. The green vehicle routing problem (G-VRP) introduced in [40] considers alternative fueled vehicles with a limited range and charging station availability as well as a constant refueling time. It is therefore often considered as the precursor of various electric vehicle routing variants with recharging. The main argument for considering recharging operations in the G-VRP is the uneven distribution of alternative fueling stations. Besides a mixed integer problem formulation of the problem that is solved using CPLEX for small instances, two construction heuristics are proposed. A computational study on randomly generated test instances as well as a real world case study are presented, showing the performance of the proposed heuristics. 
One of the major modeling challenges with these types of problems is the possibility of visiting recharging stations multiple times. The solution proposed in [40] is to create dummy nodes for every potential visit of every recharging station, thereby introducing a high level of symmetry. This type of model has been the basis for defining several electric vehicle routing problems with recharging. Note that this model does neither consider cargo capacity of the vehicles nor time windows at customer nodes. In the following, we present the model as defined in the original article, except for notation that has been slightly adapted for a unified description of the models in this section.

The problem is defined on a complete graph with node set $N^{\prime}$, consisting of a depot node $(0)$ as well as customer $(C)$ and refueling $\left(F^{\prime}\right)$ nodes. Note that the set of refueling nodes contains duplicates for every potential refueling stop. Binary decision variables $\left(x_{i j}\right)$ allow to choose whether an arc is used or not. The remaining fuel upon arrival at a node through variables $\left(y_{i}\right)$. A classical VRP model for the vehicle routing problem (VRP) where arc-dependent cost are minimized is extended by adding constraints (22)-(24) tracking the fuel level that depends on the traveled distance $\left(d_{i j}\right)$ and the fuel consumption rate per distance unit $(r)$. Visits at refueling stations always fully recharge the vehicles to their maximal capacity $(Y)$. The constraints further ensure the feasibility of the routes, including the return trip to the depot, with regards to fuel consumption.

$$
\begin{array}{ll}
y_{j} \leq y_{i}-\left(r d_{i j}\right) x_{i j}+Y\left(1-x_{i j}\right) & \forall j \in N^{\prime}, \forall i \in C, i \neq j \\
y_{j}=Y & \forall j \in F_{0}^{\prime} \\
y_{j} \geq \min \left\{r d_{j 0}, r\left(d_{j l}+d_{l 0}\right)\right\} & \forall j \in C, \forall l \in F^{\prime} .
\end{array}
$$

Heuristics have been presented improving previous results for the G-VRP $[129,130,98]$.

An exact algorithm for solving the G-VRP is described in [5]. The authors propose a set partitioning formulation where columns correspond to feasible routes. The introduction of dummy nodes for refueling stations is avoided by using a multigraph where nodes correspond to customers and arcs correspond to non-dominated feasible paths including refueling stations between two customers. Three classes of valid inequalities are used to strengthen the proposed formulation. The presented cut-and-column generation algorithm is evaluated on existing and new benchmark instances and is capable of solving instances with up to 111 customers and 28 refueling stations to optimality.

Electric vehicle routing with full recharging. The Electric vehicle routing with time windows and recharging (E-VRPTW) extends the G-VRP by 
adding variable recharging times as well as customer time windows [129]. Vehicles are always fully recharged. The recharging times are modeled as linearly depending on the used electric energy, itself linearly depending on the distance traveled. The authors propose a variable neighborhood search based metaheuristic to solve the problem. New benchmark instances are presented, introducing charging stations into the widely used Solomon instances for the VRPTW. The algorithm is also used to solve the G-VRP test instances from [40]. The presented methods are able to improve previous results for the G-VRP and other related benchmark instances.

The E-VRPTW model extends the original G-VRP model in several aspects: it introduces cargo capacity, customer time windows and battery load-dependent recharging times. An additional return depot node is introduced, thereby new node set denominations are used for the different variants including the start depot $(0)$, the end depot $(n+1)$ or both: $N_{0}^{\prime}$, $N_{n+1}^{\prime}$, and $N_{0, n+1}^{\prime}$. The objective function as well as the basic constraints remain practically unchanged. However, in this model, recharging times are now depending on the battery load level $y$ as well as a recharging rate $g$. This is modeled in the newly introduced constraint (25). Where begin of service time at each node is tracked through variables $\tau_{i}$, and arc travel times are given as $t_{i j}$. Time window and cargo constraints correspond to classical VRPTW models. Finally battery load is modeled in a similar way to the G-VRP as below:

$\begin{array}{ll}\tau_{i}+t_{i j} x_{i j}+g\left(Y-y_{i}\right)-\left(l_{0}+g Y\right)\left(1-x_{i j}\right) \leq \tau_{j} & \forall i \in F^{\prime}, \forall j \in N_{n+1}^{\prime}, i \neq j \\ 0 \leq y_{j} \leq y_{i}-\left(r d_{i j}\right) x_{i j}+Y\left(1-x_{i j}\right) & \forall j \in N_{n+1}^{\prime}, i \in C, i \neq j \\ 0 \leq y_{j} \leq Y-\left(r d_{i j}\right) x_{i j} & \forall j \in N_{n+1}^{\prime}, i \in F_{0}^{\prime}, i \neq j .\end{array}$

A fleet mix problem is studied in [56]. Besides considering conventional and electric vehicles, the authors also take into account load-dependent energy consumption based on a real-world network. An adaptive large neighborhood search approach is developed. It uses an embedded local search procedure with a surrogate function to evaluate local changes efficiently. Computational experiments on new test instances are presented, the effects of considering the actual load on the structure and quality of the obtained solutions are studied. The quality of the proposed algorithm is demonstrated by obtaining new best solutions for the E-VRPTW.

An extension of the E-VRPTW towards multiple vehicle types is considered in the Electric Fleet Size and Mix Vehicle Routing Problem with Fixed Cost, Time Windows and Recharging Stations (E-FSMFTW) in [64]. First, the E-FSMFTW model is extended with a third index in order to model the different battery and cargo capacities for the vehicle types. Second, a 
set partitioning version of the model is proposed and used in a branch-andprice algorithm for exactly solving the problem. To solve larger instances, an adaptive large neighborhood search approach is presented. A new benchmark set for the E-FSMFTW is proposed and an extensive computational study is presented. A sensitivity study shows the expected benefit of considering a fleet mix of different vehicle types in comparison to using only vehicles of a single type. The proposed algorithms were also applied to the E-VRPTW obtaining optimal solutions for some of the larger test instances.

Electric vehicle routing with partial recharging. The E-VRPTW with partial recharging $(\mathrm{PR})$ is examined in [79]. An extension of the E-VRPTW model from [129] described earlier in this section is presented. The authors introduce additional decision variables $Y_{i}$ representing the state of charge at the departure of recharging station node $i$. Some constraints of the EVRPTW need to be slightly adapted to consider partial recharging. The time required for recharging now includes the variable state of charge (28). In addition, constraints (29) track the amount of electric energy that has been recharged at each charging station. Finally, the battery capacity is enforced in (30).

$$
\begin{array}{ll}
\tau_{i}+t_{i j} x_{i j}+g\left(Y_{i}-y_{i}\right)-\left(l_{0}+g Y\right)\left(1-x_{i j}\right) \leq \tau_{j} & \forall i \in F^{\prime}, \forall j \in N_{n+1}^{\prime}, i \neq j \\
0 \leq y_{j} \leq Y_{i}-\left(r d_{i j}\right) x_{i j}+Y\left(1-x_{i j}\right) & \forall j \in N_{N+1}^{\prime}, i \in F_{0}^{\prime}, i \neq j \\
0 \leq Y_{i} \leq Y & \forall i \in F_{0}^{\prime} .
\end{array}
$$

As the model is not solvable for larger instance sizes by directly applying mathematical problem solvers such as CPLEX, the authors propose an adaptive large neighborhood search algorithm. Several removal and insertion operators are presented, including new ones specifically designed for E-VRPTW and E-VRPTW-PR. These new operators include the removal of the stations independently or along with preceding or succeeding customers and the insertion of the stations with determining the charge amount based on the recharging decisions. The performance of the new approach is evaluated on the benchmark instances from the literature. The computational study shows that the proposed approach is competitive with previous approaches for the original E-VRPTW variant. Interestingly, the partial recharging option may significantly improve the routing decisions compared to the variant with a full recharging scheme.

A matheuristic for a similar problem with partial recharging is proposed in [16]. In contrast to classical problem formulations minimizing total travel distance, total time used by the electric vehicles is considered.

An exact approach for full and partial recharging variants of the EVRPTW is presented in [32]. The authors develop a branch-and-price-and- 
cut approach for each of the problem variants. The algorithm uses specialized labeling algorithms for computing feasible routes. The presented methods are applied to slightly adapted instances from the literature and are able to solve problems with up to 100 customers and 21 recharging stations. As the instances are modified in order to be feasible for all of the studied problem variants, the optimal solutions presented in this paper are not comparable to the solutions obtained in other works on similar problems. The success of the approach is mainly attributed to the tailored resource extension functions that enable efficient labeling with constant time feasibility checking and strong dominance rules. The computational study shows that allowing multiple as well as partial recharges both help to reduce routing costs and the number of employed vehicles in comparison to the variants with single and with full recharges. The study also shows the superiority of the bidirectional labeling algorithms compared to the mono directional ones.

Electric vehicle routing with non-linear charging. Non-linear charging functions are considered in [99], where existing E-VRP models are extended using piecewise linear modeling to approximate the charging functions. Components from the existing literature are combined with specifically designed algorithms. The proposed metaheuristic combines iterated local search with set partitioning as heuristic concentration. The main feature of the approach is the separation of route sequencing and recharging decisions. The authors present and solve the fixed-route vehicle charging problem with the bijective of determining the charging decisions (where and how much to charge) minimizing the sum of the charging times and detour times while satisfying range and duration limits. A computational study compares the newly proposed non-linear charging functions with the assumptions commonly made in the literature. The results suggest that not considering non-linear charging may lead to infeasible or overly expensive solutions.

\subsubsection{Electric Location Routing Problems}

A location routing problem for battery swap locations is presented in [148]. The described problem (BSS-EV-LRP) consists of determining the locations of battery swap stations (BSS) and the vehicle routes considering the limited range of the electric vehicles. The authors develop an integer program for two problem variants: a simplified one where each vehicle can visit each BSS only once, and a variant where multiple visits are allowed. The authors further propose two metaheuristic approaches for solving BSS-EV-LRP. The authors extend existing vehicle routing benchmarks for evaluating their al- 
gorithm. Only very small instances are directly solvable using CPLEX and instances up to 480 customers are being solved using the proposed heuristics.

An adaptive variable neighborhood search approach for the same problem (BSS-EV-LRP) is presented in [65]. The authors describe how existing methods for VRPs with intermediate stops can be extended to the battery swap station version of the problem. The presented solution approach improves the results of the previously published heuristics in terms of solution quality and run times.

The electric location routing problem with time windows and partial recharging (E-LRP-TWPR) is presented in [127]. The problem generalizes the previously defined BSS-EV-LRP in several ways. It includes a time dimension, therefore introducing time windows. This allows to investigate various recharging concepts such as battery swapping (constant recharging time) and full and partial recharging. The authors further investigate several objective functions, minimizing the overall traveled distance, minimizing the number of used vehicles for a fixed number of charging stations and vice-versa, a weighted sum objective of vehicles and charging stations, as well as total costs. A basic mixed integer program is proposed as well as a strengthened formulation including preprocessing, strengthened constraints, and lower bounds on the number of necessary vehicles and charging stations. An extensive computational study shows the benefits of the strengthened formulation as well as results for the different objective functions. In subsequent work, the authors propose an adaptive large neighborhood search for the location routing problem with intra-route facilities [128]. New best known solutions for the electric location routing problem with time windows and partial recharging, as well as for the battery swap station electric vehicle location routing problem are presented. Furthermore, the competitiveness of the proposed approach is demonstrated on the electric vehicle routing problem with time windows for full and partial recharging, finding new best solutions for both problem variants.

\section{Maritime Transportation}

Maritime transportation carries about $90 \%$ of the world trade [66], so it is self-evident that it is a very important mode as regards the world economy. Using the definition in [117], green maritime transportation means achieving an acceptable environmental performance of the maritime supply chain while at the same time satisfying traditional economic criteria, therefore trying to achieve a win-win outcome. When talking about an acceptable environmental performance, in this chapter we will focus on maritime emissions. 
We mention this as there are additional maritime environmental attributes that are important, such as ballast water, oil pollution, residues, hazardous substances, ship recycling, garbage, noise, and others.

In turn, maritime emissions can be classified into several categories. Green House Gases (GHGs) include carbon dioxide $\left(\mathrm{CO}_{2}\right)$, methane $\left(\mathrm{CH}_{4}\right)$, and nitrous oxide $\left(\mathrm{N}_{2} \mathrm{O}\right)$, among others. Non-GHGs include mainly sulfur oxides $\left(\mathrm{SO}_{x}\right)$ and nitrogen oxides $\left(\mathrm{NO}_{x}\right)$. Various other pollutants, such as particulate matter (PM), volatile organic compounds (VOC), black carbon, and others, are also emitted.

As early as in 1997 in Kyoto, the United Nations Framework Conference on Climate Change (UNFCCC) has designated the International Maritime Organization (IMO) as the body responsible for regulating maritime air emissions. In 2008, the IMO adopted amendments to the MARPOL Annex VI regulations that deal with $\mathrm{SO}_{x}$ and $\mathrm{NO}_{x}$ emissions. As regards GHGs, in 2011,t the IMO adopted the Energy Efficiency Design Index (EEDI) for ships built after 2012. For each ship, its EEDI should be no more than a prescribed upper bound, which is a function of ship type and dead weight.

It has been customary to break down the spectrum of measures to reduce maritime emissions into basically three major classes. First, technological measures include more efficient (energy-saving) engines, more efficient ship hulls and designs, more efficient propellers, cleaner fuels (low carbon content, liquefied natural gas), alternative fuels (fuel cells, bio fuels, etc), devices to trap exhaust emissions (scrubbers, etc), energy recuperation devices (exhaust heat recovery systems, etc), cold ironing in ports, various kites, fuel cells, electric propulsion, and others. Compliance with EEDI, which is a design index, will mainly induce technological measures. Second, we have what we call market-based measures or MBMs. These include a tax levied on bunker fuel, Emissions Trading Schemes (ETS), and a variety of others. The IMO examined such measures recently but discussion was suspended in 2013. For a survey of MBMs see [113]. Third, and what we will focus on here, logistics-based (tactical and operational) measures include speed optimization, optimized weather routing, optimal fleet management and deployment, efficient supply chain management, and others that impact the maritime logistical operation.

We note that the partition into the above three categories is, in many respects, artificial. This is so because an MBM may induce the ship owner to adopt logistics-based measures in the short run and technological measures in the long run. Both sets of measures would result in emissions reductions. 


\begin{tabular}{l|l}
\hline Problem category (selected) & Related references (selected) \\
\hline Ship routing and scheduling (general) & {$[123],[22]$} \\
Ship routing and scheduling (tramp) & {$[7],[45],[89]$} \\
Ship routing and scheduling (offshore supply) & {$[60],[100]$} \\
Fleet deployment (liner) & {$[110],[94],[8]$} \\
Fleet size and mix (liner) & {$[4],[149],[72],[44],[111],[116]$,} \\
Speed optimization (general) & {$[102],[55],[72]$} \\
& {$[153],[121],[15]$} \\
Network design (liner) & {$[2],[107],[92]$} \\
Weather routing (general) & {$[70],[140]$} \\
Transshipment (liner) & {$[96],[58],[133]$} \\
Terminal management &
\end{tabular}

Table 1: Selected logistics-based problems and related references in maritime transportation (adapted from [117])

\subsection{Logistics-based problems}

Environmental criteria aside, we first note that the spectrum of logisticsbased problems in maritime transportation is very broad. For surveys see [22] and for liner problems [95]. These problems can be broken down in the categories broadly shown in Table 1 below. Some related references are also shown in the table (neither list is encyclopedic).

In much of the maritime transportation literature such as the above, environmental criteria such as emissions reduction are scarce, traditional economic criteria such as cost or profit optimization being the norm. But sometimes such economic criteria map directly into environmental criteria: if for instance fuel cost is the criterion, it is directly proportional to emissions, hence if fuel cost is to be minimized as an objective, so will emissions (GHG or other), and the solution is win-win. By extension, and if fuel cost is an important component of a companys total cost, a solution that minimizes such cost is likely to be close to a green solution. However, if the above is not the case, or for other objective functions, this direct relationship may cease to exist and one would need to look at environmental criteria in their own right. Even though such criteria were not very common in the past, the body of knowledge that includes such criteria has been growing in recent years.

Among logistics-based problems, a significant part of the recent literature on green maritime logistics deals with speed optimization. This is because speed reduction is an important measure to achieving both fuel cost reduction and emissions reduction, therefore it is potentially a win-win proposition.

The importance of ship speed on ship emissions can be seen, among 
others, in [114], who, inter alia, estimate $\mathrm{CO}_{2}$ emissions from the world commercial fleet broken down by ship type-size combination. According to their analysis, which was based on 2007 data taken from the IHS Fairplay ship database $(45,620$ commercial ships accounted for $)$, container ships are the top $\mathrm{CO}_{2}$ emitters in the world fleet. This was perhaps something to be expected, given the relatively high design speeds of these vessels (20-26 knots) as opposed to those carrying bulk cargoes (13-15 knots) and given the non-linear relationship between speed and fuel consumption ${ }^{4}$. What was perhaps not so obvious to expect was that just the top tier category of container vessels (712 vessels of 4,400 TEU and above) produced 110.36 million tonnes of $\mathrm{CO}_{2}$ emissions, which was higher than the 106 million tonnes produced by the entire crude oil tanker fleet (2,028 vessels). The reason is simple: speed. This means that if ship speed were to be reduced, perhaps uniformly across the board, or even selectively for some categories of vessels, emissions would be reduced too, perhaps drastically.

Reducing ship speed could also have important side benefits: cost reduction is one, and helping a depressed market in which shipping overcapacity is the norm these days is another. In that sense, reducing ship speed may conceivably be a win-win proposition.

Because of the non-linear relationship between speed and fuel consumption, it is obvious that a ship that goes slower will emit much less than the same ship going faster. If one starts with the simple way to reduce fuel costs (and by extension emissions) by reducing speed, this can be done at two levels. One level is the technological one, that is, build future ships with reduced installed horsepower so that they emit less. One of the side-effects of the EEDI index may actually be this one, building ships that, in order to be EEDI-compliant, go slower because of reduced horsepower. The first cellular container ships of the late 60 s and early 70 s that went up to 33 knots in the late 1960s when fuel was cheap are gone forever. Maersks Triple-E fleet of 18,000 TEU container ships have a design speed of 17.8 knots, down from the 20-26 knots range that has been the industrys norm, and will emit $20 \%$ less $\mathrm{CO}_{2}$ per container moved as compared to the Emma Maersk, previously the worlds largest container vessel, and $50 \%$ less than the industry average on the Asia-Europe trade lane [93].

The other level of speed reduction is the logistics-based one. At that

\footnotetext{
${ }^{4}$ The per day fuel consumption at sea is at least a cubic function of ship speed, the exponent being higher than 3 in some cases, depending on ship type. A cubic law means that, for a given ship, a 26-knot speed would burn in a day 8 times the fuel of a 13-knot speed. Per mile consumption is quadratic in this case.
} 
level, an existing ship can sail slower than its design speed. In shipping parlance, this is known as slow steaming and may involve just slowing down or even derating a ships engine, that is, reconfiguring the engine so that a lower power output is achieved so that even slower speeds can be attained. Such a reconfiguration may involve dropping a cylinder from the main engine or other measures. Depending on engine technology, slow steaming kits are provided by engine manufacturers so that ships can smoothly reduce speed at any desired level. In case speed is drastically reduced, the practice is known as super slow steaming.

At the same time, and even though win-win solutions may look as natural consequences of speed reduction, the practice may have other ramifications which may not be beneficial. In the long run, more ships will be needed to produce the same transport throughput, and this will entail some costs, some of them financial and some environmental, such as life cycle emissions due to shipbuilding and recycling. For a comprehensive analysis of life cycle emissions in maritime transport see [21].

Two fundamental exogenous factors may influence the speed decision: (a) the price of fuel, and (b) the state of the market, reflected in the prevalent freight rate. Higher fuel prices and/or lower freight rates induce lower speeds and vice versa. So slow steaming is a common practice in periods of high fuel prices and/or depressed freight rates. By contrast, ships tend to speed up whenever the market gets better or fuel prices drop. If the market is good and the freight rates are high, the ship may want to make more trips to earn more income, and this may be profitable even though fuel costs will also rise. An exception is whenever ship speed is fixed or somehow constrained by contractual obligation or by time windows that imply a prescribed speed.

Another side effect of speed reduction is that in the short run freight rates will go up once the overall transport supply shrinks because of slower speeds. Reducing speed may help a depressed market, but it is the shippers who will suffer and in fact they will do so in two ways: they will pay more, and receive their cargo later. In-transit cargo inventory costs will increase, and this may be significant for high-valued cargoes and long-haul trips. For a discussion how tanker spot rates may be impacted as a result of slow steaming see [33].

Last but not least, another possible side effect concerns effects that speed reduction may have on other modes of transport; to the extent these are alternatives to sea transport. This is the situation mostly as regards short-sea trades, in Europe but also in North America. If ships are made to go slower, shippers may be induced to prefer land-based transport alternatives, mostly road, and that may increase overall GHG emissions. Even in long-haul sce- 
narios such as the Far East to Europe trade, some cargoes may tempted to use the rail alternative (for instance via the Trans-Siberian railway) if the speed of vessels is low enough. [115] develop modal-split models that can be used to investigate such problems.

In the most recent survey of speed models of [117], 16 among the 51 surveyed papers incorporate emissions considerations, and a number of others consider fuel consumption minimization as an objective, which implies that emissions are also minimized. Papers that consider emissions include [17], [24], [34], [42], [45], [46], [55], [77], [90], [100], [114] and [116].

Speed optimization can be extended into combined ship routing and speed scenarios. A number of papers in the literature have looked at such scenarios, see for instance [72] and [44], among others. The literature on green vehicle routing in a road setting (see Section 2.2.1 of this paper) can be considered as a parallel here, although obviously the cost and emissions functions in a maritime setting are very different from those in a road setting.

Combined routing and speed scenarios in which the fuel consumption function depends on both ship speed and payload and in which fuel price, freight rate and cargo inventory costs are also taken onboard are considered in [116] for a single ship setting and in [144] for a multiple ship setting. One of the perhaps counter-intuitive results of these combined scenarios is that sailing the minimum distance route at minimum speed does not necessarily minimize emissions. This may be so whenever the minimum distance route involves a heavier load profile for the ship. Depending on ship type, the difference in fuel consumption between a fully loaded and a ballast (empty) condition can be up to $40 \%$. A result that is less surprising is that expensive cargoes sail faster and hence induce more emissions. This is to be expected if cargo inventory costs are taken into account.

Psaraftis and Kontovas [112], among other things, provide a discussion on the possible impact of slow steaming on port operations. If a port is congested, it would clearly make no sense to sail there at full speed, wasting money on fuel and producing emissions that can be avoided if ship speeds were slower. A recent initiative is the so-called 'Virtual Arrival', which has been used in order to manage the vessels' arrival times based on the experience of congestion at some discharging ports. This initiative recognizes known inefficiencies in the supply chain such as waiting to discharge because of port delays and reduces fuel consumption and, consequently, emissions by implementing a mutually-agreed reduction in a vessels speed in order to achieve an agreed arrival time at a port. After the agreement of both parties, the ship slows to the economic speed based on the revised arrival times. Once the voyage is completed, demurrage is calculated based on the 
original plans and bunker savings are split between the parties. At the same time, Californian ports have been offering monetary incentives for ocean going vessels that reduce speed down to 12 knots in the proximity of the port as an emissions reduction measure (Vessel Speed Reduction Programme - VSRP) which has seen great participation rates [152].

In separate but related initiatives, [57] and [34] developed models that combine optimizing berth allocation with reducing associated vessel emissions.

\subsection{The sulfur issue}

$\mathrm{SO}_{x}$ emissions entail an expanded set of issues. First of all, if fuel consumption is reduced due to logistics-based measures such as those described above, all emissions, including $\mathrm{SO}_{x}$, will be reduced. However, there are additional issues at play. $\mathrm{SO}_{x}$ emissions are not GHGs and the amounts of $\mathrm{SO}_{x}$ produced by ships are substantially lower than $\mathrm{CO}_{2}$. But $\mathrm{SO}_{x}$ emissions are highly undesirable as they cause acid rain and negative health effects in humans and animals. To mitigate these adverse environmental effects, the international shipping community has taken substantial policy measures. With the introduction of new limits for the content of sulfur in marine fuels in Northern European and North American Emission Control Areas (ECAs), short-sea companies operating in these areas will face substantial additional cost. As stated earlier, as of $1 / 1 / 2015$, international regulations stipulate, among other things, a $0.1 \%$ limit in the sulfur content of marine fuels, or equivalent measures limiting the percent of $\mathrm{SO}_{x}$ emissions to the same amount. In addition, the IMO has decided on a global $0.5 \%$ cap on $\mathrm{SO}_{x}$ emissions as of $1 / 1 / 2020$. Both these developments may have important logistical ramifications.

One of the obvious implications of ECAs is on ship speed, as low-sulfur fuel like Marine Gas Oil (MGO) or Marine Diesel Oil (MDO) are almost double the price of Heavy Fuel Oil (HFO). This would induce ships to slow down whenever they sail within ECAs. [46] and [43] developed models that optimize routes and speeds for ships that sail in and out of ECAs and switch fuel whenever they cross an ECA border.

Another possible and quite serious implication regards possible modal shifts. Even after the precipitous drop of fuel prices after mid 2014, which saw the prices of MGO and MDO in 2015 go lower than the price of HFO in early 2014, a significant price gap still exists, not to mention that fuel prices may rise again in the future. Unlike its deep-sea counterpart, in short-sea shipping, a freight rate increase due to more expensive fuel may induce shippers to use land-based alternatives (mainly road). A reverse 
shift of cargo would go against the EU policy to shift traffic from land to sea to reduce congestion and road emissions, and might ultimately (under certain circumstances) increase the overall level of $\mathrm{CO}_{2}$ emissions along the entire supply chain. See, among others, [26] for a discussion of relevant

problems in ECAs, and [104] for a discussion on the possible designation of the Mediterranean as a Sulphur Emission Control Area.

In a more recent project, the possible impacts of sulfur regulations on the Roll On-Roll Off sector in Northern Europe as well as possible mitigation actions and policy alternatives have been investigated, by developing enhanced modal split models that attempt to calculate the possible shifts to other modes. Several measures to mitigate or reverse the negative repercussions of such legislation have also been proposed. [151] present some of the results.

\section{4. 'Greening' Other Modes of Transport}

In this section, we very briefly review miscellaneous other transportation modes that have been analyzed from a green perspective.

\subsection{Rail transportation}

In the quest for greener transportation, rail is very important, as it is generally more environmental-friendly than road. It is thus not a surprise that rail, and particularly rail for freight, forms an important component of the transportation policy of many countries, and most notably in the EU. Yet, this prioritization has not yet been translated into the capture of an important modal share of rail vis-à-vis other land-based modes (and especially road). This is mainly because of barriers (technical and administrative) that concern incompatibility of the various rail systems with one another. Such incompatibility concerns issues such as gauge, electric traction systems, signaling systems, and others, such as work regulations, customs procedures, etc. So in order to shift traffic to rail, issues such as these will have to be dealt with in an effective way. For a discussion of relevant issues on green rail transportation, including research areas, see [1]. Whilst there is a significant body of literature devoted to railway planning, studies that explicitly consider environmental criteria seem to be few and far between. The work by [12] concerns designing rail services to minimize emissions within the broader remit of intermodal transportation, which is explored further in [120]. 


\subsection{Inland navigation}

Parallel with rail, inland navigation is another environmental-friendly mode, which can have an important role in many countries in Europe, North America and Asia (especially China). Yet, rivers and canals are not fully exploited as regards their potential to carry traffic away from road transportation, and their modal share is generally low. The question as regards inland navigation is twofold: how can it be greener in and of itself, and what can be done so that it can attract a higher share of the traffic. For a discussion of environmental (mainly emissions) issues of inland navigation, see [105].

\subsection{Air transportation}

Even though the contribution of air transportation to overall global economic growth has been very important, growth in that sector is also expected to have a number of negative consequences, including environmental impact, emissions and noise impacts, and global climate change, among others. In terms of grams of $\mathrm{CO}_{2}$ per ton-km, air ranks as the worst among transportation modes. The question then is, how can this mode of transportation become greener. To that effect, significant technological progress has been made over the last few decades to make aircraft more fuel efficient and less noisy, as well as make alternative, more environmental-friendly fuels such as biofuels more readily available and more economically viable. For a general overview of green air transportation issues, see [41].

\subsection{Green corridors}

Green corridors concern transportation corridors that have acceptable environmental characteristics, together with viable economic and logistical attributes. They encompass all surface transportation modes. Significant research has been performed, mainly in Europe, to define and benchmark green corridors, as well as devise appropriate governance schemes. Network design issues are also important here, and one of the important issues is how corridor performance can be measured in terms of specific Key Performance Indicators (KPIs). The reader is referred to EU project SuperGreen (www.supergreenproject.eu) and to [103] for more information on the concept.

\section{Conclusions}

This work set out to answer a question that concerns the role of OR in green freight transportation. Whilst we do not claim to have provided 
a complete answer, nor believe that such an endeavor is a simple task, we suggest here, on the basis of the work surveyed in this paper, that there are at least three fundamental roles that OR can continue to play in this area of research:

1. To devise methods, tools and algorithms that help design effective transportation plans that capture the trade-off between environmental and economic performance, with the ultimate goal of arriving at win-win solutions. To achieve this goal, however, one must carefully consider, for a particular freight transportation problem (a) who the players are, and the criteria by which they 'win'. The review of the current body of work in this area, at least on two major modes of transport, has revealed that problems are often solved for a single player (e.g., an individual freight operator), where the win criterion is the ability to jointly reduce internal and external costs, but with an emphasis on the former. There is room for further research looking at collectively planning for a number of players at different levels, which would welcome contributions from computational game theory to look at collaborative and competitive scenarios. It has been shown, for example, that a collaboration between multiple freight carriers can result in improved environmental performance [84, 108], but forming and maintaining the sustainability of such collaborations through financial incentives give rise to the need to solve difficult cost sharing problems [3]. If the environment is to be seen as another 'player', the 'win' aspect must also include other environmental criteria such as noise and land use, both of which have so far had a minimal, if at all, treatment within freight transportation planning. In addition, the consideration of multiple criteria will inevitably need to rely on the use of multicriteria optimization techniques. One contribution to this line of research appears in [125] that concerns the minimization of multiple criteria, including noise, for a green vehicle routing problem.

2. To inform and support policy makers by not only looking at improving the environmental performance of current ways of operation, but also taking a visionary view to look at potential developments in transportation infrastructure and equipment and deriving insightful results that would show the potential of the economic and environmental viability of such solutions. The emerging technology of electric vehicles is one such example where there already exists a body of work, the results of which are yet to be evaluated by policy makers. In particular, research on electric vehicle routing will have to include learnings from 
urban vehicle operations planning as described in Section 2.2. It will be important to consider the dynamics of energy consumption based on more detailed route information such as traffic state and external influences. In urban settings, recharging operations during the day will be rare, and the design of robust route plans for ensuring feasibility as well as low energy use will therefore become a major topic of interest. From a modeling and solving perspective, this might require to include alternative paths or even detailed path construction within the higher level route planning problems. Yet another relevant example in maritime transport is the emerging area of autonomous ships, which could radically transform maritime and port logistics in the future.

3. OR methods can also help evaluate the planning and evaluation of alternative (futuristic) solutions for freight, including the following:

- Changes in transportation infrastructure, such as running dedicated lanes in road transportation exclusive to the use of goods vehicles (trucks, lorries, vans), where parameters that have been shown to affect emissions (e.g., speed and road drag) can be controlled to a larger degree.

- Within road transport, looking into factors that influence driver behavior, and ways in which driver training should be (re-)designed (for example, to maintain a smooth speed profile and to avoid aggressive driving) so that a better environmental performance can be achieved.

- Within maritime transport, addressing issues such as increased interoperability between ship and port as well as improving the efficiency of the interface across modes.

- Re-thinking ways in which carbon costs are set and justifying, or otherwise, the need for introducing taxes, tolls, carbon caps or other market-based measures with a view to reducing emissions.

- Informing technological developments such as self-driving or autonomous trucks or ships, as well as the effect of vehicle design (e.g., shape, aerodynamics, engine type and efficiency) on the resulting freight transportation plans.

One must bear in mind that there is a range of possibilities here in relation to greening freight transportation, which are broad in their nature and often go beyond the remit of OR, and that OR on its own should not be seen as a 'one-size-fits-all' remedy for all such issues. However, OR could and should be used to inform the development of new solutions, and to evaluate the 
economic, social and environmental viability of these solutions, and do so in collaboration with other disciplines.

\section{Acknowledgements}

This work was supported in part with public funding within the scope of the French Program "Investissements d'Avenir" and by an internal grant at the Technical University of Denmark. Thanks are due to two reviewers for their comments on an earlier version of this paper.

\section{References}

[1] P. T. Aditjandra, T. H. Zunder, D. Islam, and R. Palacin. Green rail transportation: Improving rail freight to support green corridors. In H. N. Psaraftis, editor, Green Transportation Logistics: The Quest for Win-Win Solutions, pages 413-454. Springer, Cham, 2016.

[2] R. Agarwal and Ö. Ergun. Ship scheduling and network design for cargo routing in liner shipping. Transportation Science, 42(2):175196, 2008.

[3] J. Allen, T. Bektaş, T. Cherrett, A. Friday, F. McLeod, M. Piecyk, M. Piotrowska, and M.Z. Austwick. Enabling a freight traffic controller for collaborative multidrop urban logistics: Practial and theoretical challenges. Transportation Research Record: Journal of the Transportation Research Board, 2609:77-84, 2017.

[4] J.F. Alvarez, P. Tsilingiris, E.S. Engebrethsen, and N.M. Kakalis. Robust fleet sizing and deployment for industrial and independent bulk ocean shipping companies. INFOR: Information Systems and Operational Research, 49(2):93-107, 2011.

[5] J. Andelmin and E. Bartolini. An exact algorithm for the green vehicle routing problem. Transportation Science, 51(4):1288-1303, 2017.

[6] A. Anderluh, V.C. Hemmelmayr, and P.C. Nolz. Synchronizing vans and cargo bikes in a city distribution network. Central European Journal of Operations Research, 25(2):345-376, 2017.

[7] H. Andersson, J.M. Duesund, and K. Fagerholt. Ship routing and scheduling with cargo coupling and synchronization constraints. Computers and Industrial Engineering, 61(4):1107-1116, 2011. 
[8] H. Andersson, K. Fagerholt, and K. Hobbesland. Integrated maritime fleet deployment and speed optimization: Case study from roro shipping. Computers and Operations Research, 55:233-240, 2015.

[9] A. Artmeier, J. Haselmayr, M. Leucker, M. Sachenbacher, et al. The optimal routing problem in the context of battery-powered electric vehicles. In Workshop: CROCS at CPAIOR-10, Second International Workshop on Constraint Reasoning and Optimization for Computational Sustainability, Bologna, Italy, 2010.

[10] H. Asamer, A. Graser, B. Heilmann, and M. Ruthmair. Sensitivity analysis for energy demand estimation of electric vehicles. Transportation Research Part D: Transport and Environment, 46:182-199, 2016.

[11] M. Barth, T. Younglove, and G. Scora. Development of a heavyduty diesel modal emissions and fuel consumption model. Technical Report UCB-ITS-PRR-2005-1, California PATH Program, Institute of Transportation Studies, University of California at Berkeley, 2005.

[12] J. Bauer, T. Bektaş, and T.G. Crainic. Minimizing greenhouse gas emissions in intermodal freight transport: an application to rail service design. Journal of the Operational Research Society, 61(3):530-542, 2010 .

[13] T. Bektaş and G. Laporte. The Pollution-Routing Problem. Transportation Research Part B: Methodological, 45(8):1232-1250, 2011.

[14] G. Brandstätter, C. Gambella, M. Leitner, E. Malaguti, F. Masini, J. Puchinger, M. Ruthmair, and D. Vigo. Overview of optimization problems in electric car-sharing system design and management. In H. Dawid, K.F. Doerner, G. Feichtinger, P.M. Kort, and A. Seidl, editors, Dynamic Perspectives on Managerial Decision Making: Essays in Honor of Richard F. Hartl, pages 441-471. Springer International Publishing, 2016.

[15] B.D. Brouer, J.F. Alvarez, C.E. Plum, D. Pisinger, and M.M. Sigurd. A base integer programming model and benchmark suite for linershipping network design. Transportation Science, 48(2):281-312, 2013.

[16] M. Bruglieri, S. Mancini, F. Pezzella, O. Pisacane, and S. Suraci. A three-phase matheuristic for the time-effective electric vehicle routing 
problem with partial recharges. Electronic Notes in Discrete Mathematics, 58:95-102, 2017. 4th International Conference on Variable Neighborhood Search.

[17] P. Cariou and A. Cheaitou. The effectiveness of a European speed limit versus an international bunker-levy to reduce CO2 emissions from container shipping. Transportation Research Part D, 17(2):116-123, 2012 .

[18] L.C. Casals, E. Martinez-Laserna, B. Amante Garca, and N. Nieto. Sustainability analysis of the electric vehicle use in europe for co2 emissions reduction. Journal of Cleaner Production, 127:425 - 437, 2016.

[19] D. Cattaruzza, N. Absi, D. Feillet, and J. González-Feliu. Vehicle routing problems for city logistics. EURO Journal on Transportation and Logistics, 6(1):51-79, 2017.

[20] M. Çimen and M. Soysal. Time-dependent green vehicle routing problem with stochastic vehicle speeds: An approximate dynamic programming algorithm. Transportation Research Part D: Transport and Environment, 54:82-98, 2017.

[21] S.D. Chatzinikolaou and N.P. Ventikos. Critical analysis of air emissions from ships: Lifecycle thinking and results. In H.N. Psaraftis, editor, Green Transportation Logistics: in Search for Win-Win Solutions, pages 387-412. Cham, 2016.

[22] M. Christiansen, K. Fagerholt, B. Nygreen, and D. Ronen. Ship routing and scheduling in the new millennium. European Journal of Operational Research, 228:467-483, 2013.

[23] R.G. Conrad and M.A. Figliozzi. The recharging vehicle routing problem. In Proceedings of the IIE Annual Conference 2011, Reno, NV, 2011.

[24] J. Corbett, H. Wang, and J. Winebrake. The effectiveness and costs of speed reductions on emissions from international shipping. Transportation Research Part D: Transport and Enviroment, 14(8):593-598, 2009.

[25] T. G. Crainic. City logistics. In Paul Gray Harvey J. Greenberg ZhiLong Chen, S. Raghavan, editor, INFORMS Tutorials in Operations 
Research: State-of-the-Art Decision-Making Tools in the InformationIntensive Age, chapter 9, pages 181-212.

[26] K. Cullinane and R. Bergqvist. Emission control areas and their impact on maritime transport. Transportation Research Part D, 28:1-5, 2014.

[27] R. Dekker, J. Bloemhof, and I. Mallidis. Operations research for green logistics-an overview of aspects, issues, contributions and challenges. European Journal of Operational Research, 219(3):671-679, 2012.

[28] E. Demir, T. Bektaş, and G. Laporte. A comparative analysis of several vehicle emission models for road freight transportation. Transportation Research Part D: Transport and Environment, 16(5):347357, 2011.

[29] E. Demir, T. Bektaş, and G. Laporte. An adaptive large neighborhood search heuristic for the pollution-routing problem. European Journal of Operational Research, 223(2):346-359, 2012.

[30] E. Demir, T. Bektaş, and G. Laporte. The bi-objective PollutionRouting Problem. European Journal of Operational Research, 232(3): 464-478, 2014.

[31] E. Demir, T. Bektaş, and G. Laporte. A review of recent research on green road freight transportation. European Journal of Operational Research, 237(3):775-793, 2014.

[32] G. Desaulniers, F. Errico, S. Irnich, and M. Schneider. Exact algorithms for electric vehicle-routing problems with time windows. $O p$ erations Research, 64(6):1388-1405, 2016.

[33] J.W. Devanney. Solving elastic transportation networks. center for tankship excellence. Technical report, 2007. Available at www.c4tx. org.

[34] Y. Du, Q. Chen, X. Quan, L. Long, and R.Y.K. Fung. Berth allocation considering fuel consumption and vessel emissions. Transportation Research Part E, 47(6):1021-1037, 2011.

[35] J.F. Ehmke. Integration of Information and Optimization Models for Routing in City Logistics. Springer, Heidelberg, 2012. 
[36] J.F. Ehmke, A.M. Campbell, and B.W. Thomas. Optimizing for costs and emissions in vehicle routing in urban areas. Technical Report, available at https://www. researchgate. net/publication/304657714_ Optimizing_for_Costs_and_ Emissions_in_Vehicle_Routing_in_Urban_Areas, 2016.

[37] J.F. Ehmke, A.M. Campbell, and B.W. Thomas. Data-driven approaches for emissions-minimized paths in urban areas. Computers $\&$ Operations Research, 67:34-47, 2016.

[38] J.F. Ehmke, A.M. Campbell, and B.W. Thomas. Vehicle routing to minimize time-dependent emissions in urban areas. European Journal of Operational Research, 251(2):478-494, 2016.

[39] J. Eisner, S. Funke, and S. Storandt. Optimal route planning for electric vehicles in large networks. In Proceedings of the TwentyFifth AAAI Conference on Artificial Intelligence, pages 1108-1113, San Francisco, 2011.

[40] S. Erdoğan and E. Miller-Hooks. A green vehicle routing problem. Transportation Research Part E: Logistics and Transportation Review, 48(1):100-114, 2012.

[41] A. Evans. Emissions and aviation: Towards greener air transport. In H.N. Psaraftis, editor, Green Transportation Logistics: The Quest for Win-Win Solutions, pages 81-121. Springer, Cham, 2016.

[42] J. Faber, M. Freund, M. Köpke, and D. Nelissen. Going slow to reduce emissions: can the current surplus of maritime transport capacity be turned into an opportunity to reduce ghg emissions? Technical report, 2010. Available at http://www.seas-at-risk.org/.

[43] K. Fagerholt and H.N. Psaraftis. On two speed optimization problems for ships that sail in and out of emission control areas. Transportation Research Part D, 39:56-64, 2015.

[44] K. Fagerholt and D. Ronen. Bulk ship routing and scheduling: solving practical problems may provide better results. Maritime Policy and Management, 40(1):48-64, 2013.

[45] K. Fagerholt, G. Laporte, and I. Norstad. Reducing fuel emissions by optimizing speed on shipping routes. Journal of the Operational Research Society, 61(3):523-529, 2010. 
[46] K. Fagerholt, N. Gausel, J. Rakke, and H. Psaraftis. Maritime routing and speed optimization with emission control areas. Transportation Research Part C, 52:57-63, 2015.

[47] Y. Feng, R.-Q. Zhang, and G. Jia. Vehicle Routing Problems with Fuel Consumption and Stochastic Travel Speeds. Mathematical Problems in Engineering, 2017. In press.

[48] M. Figliozzi. Vehicle Routing Problem for Emissions Minimization. Transportation Research Record: Journal of the Transportation Research Board, 2197:1-7, 2010.

[49] D.J. Forkenbrock. External costs of intercity truck freight transportation. Transportation Research Part A: Policy and Practice, 33(7): 505-526, 1999.

[50] D.J. Forkenbrock. Comparison of external costs of rail and truck freight transportation. Transportation Research Part A: Policy and Practice, 35(4):321-337, 2001.

[51] A. Franceschetti, D. Honhon, T. Van Woensel, T. Bektaş, and G. Laporte. The time-dependent pollution-routing problem. Transportation Research Part B: Methodological, 56:265-293, 2013.

[52] R. Fukasawa, Q. He, and Y. Song. A branch-cut-and-price algorithm for the energy minimization vehicle routing problem. Transportation Science, 50(1):23-34, 2015.

[53] R. Fukasawa, Q. He, F. Santos, and Y. Song. A joint routing and speed optimization problem. arXiv preprint arXiv:1602.08508, 2016.

[54] R. Fukasawa, Q. He, and Y. Song. A disjunctive convex programming approach to the pollution-routing problem. Transportation Research Part B: Methodological, 94:61-79, 2016.

[55] K.G. Gkonis and H.N. Psaraftis. Modelling tankers optimal speed and emissions. In Proceedings of the 2012 Annual Meeting of the Society of Naval Architects 85 Marine Engineers, volume 120, pages 90-115, Rhode Island, 2012.

[56] D. Goeke and M. Schneider. Routing a mixed fleet of electric and conventional vehicles. European Journal of Operational Research, 245 (1):81-99, 2015. 
[57] M. Golias, M. Boile, S. Theofanis, and C. Efstathiou. The berthscheduling problem: Maximizing berth productivity and minimizing fuel consumption and emissions production. Transportation Research Record: Journal of the Transportation Research Board, pages 20-27, 2010 .

[58] A.V. Goodchild and C.F. Daganzo. Crane double cycling in container ports: planning methods and evaluation. Transportation Research Part B, 41(8):875-891, 2007.

[59] P.-O. Groß, J. F. Ehmke, I. Haas, and D.C. Mattfeld. Evaluation of alternative paths for reliable routing in city logistics. In D. EsztergarKiss, T. Matrai, J. Toth, and I. Varga, editors, Proceedings of EWGT 2017 - Transportation Research Procedia, volume 27, pages 1195-1202. Elsevier, 2017.

[60] E.E. Halvorsen-Weare and K. Fagerholt. Robust supply vessel planning. In Pahl, J. and Reiners, T. and Voß, S., editor, Network Optimization, chapter 11, pages 559-573. Springer, Berlin Heidelberg, 2011.

[61] I. Harris, V. Sanchez-Rodrigues, M. Naim, and C. Mumford. Restructuring road freight networks within supply chains. In Alan McKinnon, Michael Browne, Maja Piecyk, and Anthony Whiteing, editors, Green Logistics: Improving the environmental sustainability of logistics, chapter 6, pages 123-147. Kogan Page, London, 2015.

[62] H. Heni, L.C. Coelho, and J. Renaud. Time-dependent quickest path problem with emission minimization. Technical Report CIRRELT217-62, 2017.

[63] J. Hickman, D. Hassel, R. Joumard, Z. Samaras, and S. Sorenson. Meet-methodology for calculating transport emissions and energy consumption. european commission, dg vii. Technical report, 1999. Available at https://trimis.ec.europa.eu/sites/default/ files/project/documents/meet.pdf (Accessed 21 September 2017).

[64] G. Hiermann, J. Puchinger, S. Ropke, and R.F. Hartl. The electric fleet size and mix vehicle routing problem with time windows and recharging stations. European Journal of Operational Research, 252 (3):995-1018, 2016. 
[65] J. Hof, M. Schneider, and D. Goeke. Solving the battery swap station location-routing problem with capacitated electric vehicles using an avns algorithm for vehicle-routing problems with intermediate stops. Transportation Research Part B: Methodological, 97:102-112, 2017.

[66] J. Hoffmann et al. Review of maritime transport 2016. In United Nations Conference on Trade and Development, Geneva, 2016.

[67] J.N. Hooker. Optimal driving for single-vehicle fuel economy. Transportation Research Part A: General, 22(3):183-201, 1988.

[68] J.N. Hooker, A.B. Rose, and G.F. Roberts. Optimal control of automobiles for fuel economy. Transportation Science, 17(2):146-167, 1983.

[69] H. Hosseini-Nasab and P. Lotfalian. Green routing for trucking systems with classification of path types. Journal of Cleaner Production, 146:228-233, 2017.

[70] C.I. Hsu and Y.P. Hsieh. Direct versus terminal routing on a maritime hub-and-spoke container network. Journal of Marine Science and Technology, 13(3):209-217, 2005.

[71] Y. Huang, L. Zhao, T. Van Woensel, and J.-P. Gross. Time-dependent vehicle routing problem with path flexibility. Transportation Research Part B: Methodological, 95:169-195, 2017.

[72] L.M. Hvattum, I. Norstad, K. Fagerholt, and G. Laporte. Analysis of an exact algorithm for the vessel speed optimization problem. Networks, 62(2):132-135, 2013.

[73] T. Hwang and Y. Ouyang. Urban Freight Truck Routing under Stochastic Congestion and Emission Considerations. Sustainability, 7(6):6610-6625, 2015.

[74] O. Jabali, T. Van Woensel, and A.G. de Kok. Analysis of Travel Times and CO2 Emissions in Time-Dependent Vehicle Routing. Production and Operations Management, 21(6):1060-1074, 2012.

[75] Ehsan Jafari and Stephen D. Boyles. Multicriteria stochastic shortest path problem for electric vehicles. Networks and Spatial Economics, 17(3):1043-1070, 2017. 
[76] M. Janic. Modelling the full costs of an intermodal and road freight transport network. Transportation Research Part D: Transport and Environment, 12(1):33-44, 2007.

[77] G.N. Kapetanis, K.G. Gkonis, and H.N. Psaraftis. Estimating the operational effect of a bunker levy: the case of handymax bulk carriers. In Transportation Research Arena 2014, Paris, 2014.

[78] İ. Kara, B.Y. Kara, and M.K. Yetis. Energy Minimizing Vehicle Routing Problem. In Combinatorial Optimization and Applications, Lecture Notes in Computer Science, pages 62-71. Springer, Berlin, Heidelberg, 2007.

[79] M. Keskin and B. Çatay. Partial recharge strategies for the electric vehicle routing problem with time windows. Transportation Research Part C: Emerging Technologies, 65:111-127, 2016.

[80] Ç. Koç, T. Bektaş, O. Jabali, and G. Laporte. The fleet size and mix pollution-routing problem. Transportation Research Part B: Methodological, 70:239-254, 2014.

[81] Ç. Koç, T. Bektaş, O. Jabali, and G. Laporte. The impact of depot location, fleet composition and routing on emissions in city logistics. Transportation Research Part B: Methodological, 84:81-102, 2016.

[82] H.W. Kopfer, J. Schönberger, and H. Kopfer. Reducing greenhouse gas emissions of a heterogeneous vehicle fleet. Flexible Services and Manufacturing Journal, 26(1-2):221-248, 2014.

[83] F. Köster, M.W. Ulmer, and D.C. Mattfeld. Cooperative Traffic Control Management for City Logistic Routing. Transportation Research Procedia, 10:673-682, 2015.

[84] M.A. Krajewska, H. Kopfer, G. Laporte, S. Ropke, and G. Zaccour. Horizontal cooperation among freight carriers: request allocation and profit sharing. Journal of the Operational Research Society, 59(11): 1483-1491, 2008.

[85] R. Kramer, N. Maculan, A. Subramanian, and T. Vidal. A speed and departure time optimization algorithm for the pollution-routing problem. European Journal of Operational Research, 247(3):782-787, 2015 . 
[86] Y. Kuo. Using simulated annealing to minimize fuel consumption for the time-dependent vehicle routing problem. Computers $\&$ Industrial Engineering, 59(1):157-165, 2010.

[87] G. Laporte. Scheduling issues in vehicle routing. Annals of Operations Research, 236(2):463-474, 2016.

[88] C. Lin, K. L. Choy, G. T. S. Ho, S. H. Chung, and H. Y. Lam. Survey of Green Vehicle Routing Problem: Past and future trends. Expert Systems with Applications, 41(4):1118-1138, 2014.

[89] D.-Y. Lin and H.-Y. Liu. Combined ship allocation, routing and freight assignment in tramp shipping. Transportation Research Part E, 47(4): 414-431, 2011.

[90] H. Lindstad, B.E. Asbjørnslett, and A.H. Strømman. Reductions in greenhouse gas emissions and cost by shipping at lower speeds. Energy Policy, 39(6):3456-3464, 2011.

[91] B. Liu, D. Ghosal, C.-N. Chuah, and H.M. Zhang. Reducing greenhouse effects via fuel consumption-aware variable speed limit (fc-vsl). IEEE Transactions on Vehicular Technology, 61(1):111-122, 2012.

[92] H.K. Lo and M.R. McCord. Adaptive ship routing through stochastic ocean currents: General formulations and empirical results. Transportation Research Part A, 32(7):547-561, 1998.

[93] Maersk. Building the world's biggest ship. Technical report, 2013. Available at http://www.maersk. com/innovation/leadingthroughinnovation/pages/ buildingtheworldsbiggestship.aspx.

[94] Q. Meng and S. Wang. Optimal operating strategy for a long-haul liner service route. European Journal of Operational Research, 215(1): 105-114, 1997.

[95] Q. Meng, S. Wang, H. Andersson, and K. Thun. Containership routing and scheduling in liner shipping: overview and future research directions. Transportation Science, 48(2):265-280, 2013.

[96] L. Moccia, J.F. Cordeau, M. Gaudioso, and G. Laporte. A branchand-cut algorithm for the quay crane scheduling problem in a container terminal. Naval Research Logistics, 53(1):45-59, 2006. 
[97] V.V. Monastyrsky and I.M. Golownykh. Rapid computation of optimal control for vehicles. Transportation Research Part B: Methodological, 27(3):219-227, 1993.

[98] A. Montoya, C. Guéret, J.E. Mendoza, and J.G. Villegas. A multispace sampling heuristic for the green vehicle routing problem. Transportation Research Part C: Emerging Technologies, 70:113-128, 2016.

[99] A. Montoya, C. Guéret, J.E. Mendoza, and J.G. Villegas. The electric vehicle routing problem with nonlinear charging function. Transportation Research Part B: Methodological, 103:87-110, 2017.

[100] E.K. Norlund and I. Gribkovskaia. Reducing emissions through speed optimization in supply vessel operations. Transportation Research Part D, 23:3456-3464, 2013.

[101] N. Norouzi, M. Sadegh-Amalnick, and R. Tavakkoli-Moghaddam. Modified particle swarm optimization in a time-dependent vehicle routing problem: minimizing fuel consumption. Optimization Letters, 11(1):121-134, 2017.

[102] I. Norstad, K. Fagerholt, and G. Laporte. Tramp ship routing and scheduling with speed optimization. Transportation Research Part $C$, 19:853-865, 2011.

[103] G. Panagakos. Green corridors basics. In H.N. Psaraftis, editor, Green Transportation Logistics: The Quest for Win-Win Solutions, pages 81-121. Springer, Cham, 2016.

[104] G. Panagakos, I.V. Stamatopoulou, and H.N. Psaraftis. The possible designation of the mediterranean as a seca: a case study. Transportation Research Part D, 28:74-90, 2014.

[105] G. Pauli. Emissions and inland navigation. In H.N. Psaraftis, editor, Green Transportation Logistics: The Quest for Win-Win Solutions. Springer, Cham, 2016.

[106] S. Pelletier, O. Jabali, and G. Laporte. Goods distribution with electric vehicles: Review and research perspectives. Transportation Science, 50(1):3-22, 2016.

[107] A.N. Perakis and N.A. Papadakis. Minimal time vessel routing in a time-dependent environment. Transportation Science, 23(4):266-276, 1989. 
[108] E. Pérez-Bernabeu, A.A. Juan, J. Faulin, and B.B. Barrios. Horizontal cooperation in road transportation: a case illustrating savings in distances and greenhouse gas emissions. International Transactions in Operational Research, 22(3):585-606, 2015.

[109] M. Piecyk. Carbon auditing of companies, supply chains and products. In Alan McKinnon, Michael Browne, Maja Piecyk, and Anthony Whiteing, editors, Green Logistics: Improving the environmental sustainability of logistics, chapter 3, pages 56-79. Kogan Page, London, 2015.

[110] B.J. Powell and A.N. Perakis. Fleet deployment optimization for liner shipping: An integer programming model. Maritime Policy and Management, 24(2):183-192, 1997.

[111] H. N. Psaraftis and C. A. Kontovas. Speed models for energy-efficient maritime transportation: A taxonomy and survey. Transportation Research Part C, 26:331-351, 2013.

[112] H. N. Psaraftis and C.A. Kontovas. Slow steaming in maritime transportation: fundamentals, trade-offs, and decision models. In C.Y. Lee and Q. Meng, editors, Handbook of Ocean Container Transportation Logistics: Making Global Supply Chains Effective, chapter 11, pages 315-358. Springer, Cham, 2015.

[113] H.N. Psaraftis. Market-based measures for greenhouse gas emissions from ships: a review. WMU Journal of Maritime Affairs, 11(2):211232,2012 .

[114] H.N. Psaraftis and C.A. Kontovas. CO2 emissions statistics for the world commercial fleet. WMU Journal of Maritime Affairs, 8(1):1-25, 2009 .

[115] H.N. Psaraftis and C.A. Kontovas. Balancing the economic and environmental performance of maritime transportation. Transportation Research Part D, 15(8):458-462, 2010.

[116] H.N. Psaraftis and C.A. Kontovas. Ship speed optimization: Concepts, models and combined speed-routing scenarios. Transportation Research Part C: Emerging Technologies, 44:52-69, 2014.

[117] H.N. Psaraftis and C.A. Kontovas. Green maritime transportation: Speed and route optimization. In H.N. Psaraftis, editor, Green Trans- 
portation Logistics: in Search for Win-Win Solutions, pages 299-349. 2016.

[118] J. Qian and R. Eglese. Finding least fuel emission paths in a network with time-varying speeds. Networks, 63(1):96-106, 2014.

[119] J. Qian and R. Eglese. Fuel emissions optimization in vehicle routing problems with time-varying speeds. European Journal of Operational Research, 248(3):840-848, 2016.

[120] Y. Qu, T. Bektaş, and J. Bennell. Sustainability SI: multimode multicommodity network design model for intermodal freight transportation with transfer and emission costs. Networks and Spatial Economics, 16(1):303-329, 2016.

[121] L.B. Reinhardt and D. Pisinger. A branch and cut algorithm for the container shipping network design problem. Flexible Services and Manufacturing Journal, 24(3):349-374, 2014.

[122] W.F. Rogge, L.M. Hildemann, M.A. Mazurek, G.R. Cass, and B.R.T. Simoneit. Sources of fine organic aerosol. 3. road dust, tire debris, and organometallic brake lining dust: roads as sources and sinks. Environmental Science \& Technology, 27(9):1892-1904, 1993.

[123] D. Ronen. The effect of oil price on the optimal speed of ships. Journal of the Operational Research Society, 33:1035-1040, 1982.

[124] M. Ross. Fuel efficiency and the physics of automobiles. Contemporary Physics, 38(6):381-394, 1997.

[125] B. Sawik, J. Faulin, and E. Pérez-Bernabeu. A multicriteria analysis for the Green VRP: A case discussion for the distribution problem of a spanish retailer. Transportation Research Procedia, 22:305-313, 2017.

[126] A. Sbihi and R.W. Eglese. Combinatorial optimization and green logistics. Annals of Operations Research, 175(1):159-175, 2010.

[127] M. Schiffer and G. Walther. The electric location routing problem with time windows and partial recharging. European Journal of Operational Research, 260(3):995-1013, 2017.

[128] M. Schiffer and G. Walther. An adaptive large neighborhood search for the location-routing problem with intra-route facilities. Transportation Science, 52(2):331-352, 2018. 
[129] M. Schneider, A. Stenger, and D. Goeke. The electric vehicle-routing problem with time windows and recharging stations. Transportation Science, 48(4):500-520, 2014.

[130] M. Schneider, A. Stenger, and J. Hof. An adaptive vns algorithm for vehicle routing problems with intermediate stops. OR Spectrum, 37 (2):353-387, 2015.

[131] M. Sivak and B. Schoettle. Eco-driving: Strategic, tactical, and operational decisions of the driver that influence vehicle fuel economy. Transport Policy, 22:96-99, 2012.

[132] M. Soysal and M. Çimen. A Simulation Based Restricted Dynamic Programming approach for the Green Time Dependent Vehicle Routing Problem. Computers \& Operations Research, 88:297-305, 2017.

[133] R. Stahlbock and S. Voss. Operations research at container terminals: a literature update. OR Spectrum, 30(1):1-52, 2008.

[134] M. Strehler, S. Merting, and C. Schwan. Energy-efficient shortest routes for electric and hybrid vehicles. Transportation Research Part B: Methodological, 103:111-135, 2017.

[135] T.M. Sweda, I.S. Dolinskaya, and D. Klabjan. Optimal recharging policies for electric vehicles. Transportation Science, 51(2):457-479, 2017.

[136] T.M. Sweda, I.S. Dolinskaya, and D. Klabjan. Adaptive routing and recharging policies for electric vehicles. Transportation Science, 51(4): 1326-1348, 2017.

[137] E. Taniguchi and R.G. Thompson. Innovations in City Logistics. Nova Science Publishers Inc, New York, 1st edition, 2008.

[138] F. Tricoire and S.N. Parragh. Investing in logistics facilities today to reduce routing emissions tomorrow. Transportation Research Part B: Methodological, 103:56-67, 2017.

[139] S. Ubeda, F.J. Arcelus, and J. Faulin. Green logistics at eroski: A case study. International Journal of Production Economics, 131(1): 44-51, 2011.

[140] S. Wang and Q. Meng. Sailing speed optimization for container ships in a liner shipping network. Transportation Research Part E, 48(3): 701-714, 2012. 
[141] L. Wen and R. Eglese. Minimum cost VRP with time-dependent speed data and congestion charge. Computers 8 Operations Research, 56: 41-50, 2015.

[142] L. Wen and R. Eglese. Minimizing $\mathrm{CO}_{2}$ emissions by setting a road toll. Transportation Research Part D: Transport and Environment, 44: $1-13,2016$.

[143] L. Wen, B. Çatay, and R. Eglese. Finding a minimum cost path between a pair of nodes in a time-varying road network with a congestion charge. European Journal of Operational Research, 236(3):915-923, 2014 .

[144] M. Wen, D. Pacino, C. Kontovas, and H. N. Psaraftis. A multiple ship routing and speed optimization problem under time, cost and environmental objectives. Transportation Research Part D, 52:303$321,2017$.

[145] World Energy Council. Global transport scenarios 2050. Technical report, London, 2011. Available at https://www.worldenergy.org/ wp-content/uploads/2012/09/wec_transport_scenarios_2050. pdf.

[146] Y. Xiao and A. Konak. The heterogeneous green vehicle routing and scheduling problem with time-varying traffic congestion. Transportation Research Part E: Logistics and Transportation Review, 88:146166, 2016.

[147] Y. Xiao and A. Konak. A genetic algorithm with exact dynamic programming for the green vehicle routing \& scheduling problem. Journal of Cleaner Production, 167:1450-1463, 2017.

[148] J. Yang and H. Sun. Battery swap station location-routing problem with capacitated electric vehicles. Computers $\& 5$ Operations Research, $55: 217-232,2015$.

[149] Q. Zeng and Z. Yang. Model integrating fleet design and ship routing problems for coal shipping. In Y. Shi, G.D. van Albada, J. Dongarra, and Sloot P.M.A, editors, Lecture Notes in Computer Science, Proceedings of the 2007 International Conference on Computational Science, volume 4489, pages 1000-1003, Berlin, Heidelberg, 2007. Springer. 
[150] M. Zhou, H. Jin, and W. Wang. A review of vehicle fuel consumption models to evaluate eco-driving and eco-routing. Transportation Research Part D: Transport and Environment, 49:203-218, 2016.

[151] T. Zis and H.N Psaraftis. The implications of the new sulphur limits on the European Ro-Ro sector. Transportation Research Part D, 52: 185-201, 2017.

[152] T. Zis, R.J. North, P. Angeloudis, W.Y. Ochieng, and M.G.H. Bell. Evaluation of cold ironing and speed reduction policies to reduce ship emissions near and at ports. Maritime Economics and Logistics, 16: 371-398, 2014.

[153] T. Zis, R.J. North, P. Angeloudis, W.Y. Ochieng, and M.G.H. Bell. Environmental balance of shipping emissions reduction strategies. Transportation Research Record: Journal of the Transportation Research Board, pages 25-33, 2015. 